\title{
Analysis of response systems in Pavlovian conditioning reveals rapidly versus slowly acquired conditioned responses: Support for two factors, implications for behavior and neurobiology
}

\author{
ROBERT C. LENNARTZ and NORMAN M. WEINBERGER \\ University of California Irvine, California
}

\begin{abstract}
A review of the literature on aversive Pavlovian (classical) conditioning was conducted to determine whether various conditioned responses (CRs) develop at the same or at different rates. Statistical analyses revealed a bimodal distribution of the rates of acquisition of various types of CRs. Rapid acquisition ( $M=5.7$ trials to first consistent $C R)$ occurs for conditioned suppression and changes in galvanic skin response, blood pressure, respiration, pupil size, and heart rate. Slower acquisition ( $M=71.3$ trials) characterizes nictitating membrane, eyelid, and flexion CRs. Differences in conditioned stimulus intensity, unconditioned stimulus intensity, intertrial interval, and interstimulus interval between the two groups cannot explain the dichotomy. Studies of concurrent measurement of more than one type of CR further support the "fast/slow" CR distinction. The findings support two-factor theories of Pavlovian conditioning. The results are discussed with regard to various two-factor learning theories, and the implications for behavioral and neurobiological studies of learning are considered.
\end{abstract}

Since the pioneering work of Pavlov (1927), classical conditioning has been used in an enormous array of behavioral and neurobiological studies. The fact that this research continues unabated is a testament to the power and richness of Pavlovian classical conditioning as a research tool. It also indicates that a satisfactory understanding of such learning is still sought.

Many different behavioral response systems have been studied. A question that arises is, How "equal" are the various systems that have been recorded in Pavlovian conditioning? As an example, consider a hypothetical experiment in which simultaneous recordings are obtained from all possible response systems. Would conditioned responses (CRs) appear in all systems at the same time? A number of theorists have suggested that the answer to this

This research was supported by the National Institutes of Mental Health (MH 14599 and MH 09600), the National Science Foundation (BNS 83-17940, to N.M.W.), the Office of Naval Research (N00014-84-K0391, N00014-87-K-0433, and N00014-91-J-1193, all to N.M.W.), and The Monsanto Corporation. We thank Jacquie Weinberger for her secretarial assistance. When this research was undertaken, both authors were affiliated with The Center for the Neurobiology of Learning and Memory and the Department of Psychobiology at U.C. Irvine. Robert C. Lennartz is currently in the Department of Psychology at The University of Virginia, Charlottesville, VA 22903. Correspondence concerning this article should be addressed to $N$. M. Weinberger, CNLM/Bonney Center, University of California, Irvine, CA 92717 (e-mail: nweinberger1@uci.bitnet). question is "no." They have argued for a bimodal distribution of acquisition rates, and for two-process theories of conditioning (Konorski, 1967; Mowrer, 1947; Schlosberg, 1937).

The purpose of this article is to assess whether the acquisition rates in the various response systems are the same throughout Pavlovian defensive (aversive) conditioning. If not, do the findings support specific two-process theories? To obtain data relevant to this issue, we surveyed and systematically analyzed the literature for nine different response systems. Although Weinberger (1982) provided a small review of this type earlier which suggested a bimodal distribution, the survey presented here is considerably more extensive and is analyzed statistically. We will also explicitly consider problems involved in drawing conclusions from acquisition data (Rescorla, 1988).

\section{RESPONSE SYSTEMS REVIEWED}

The responses that have been reviewed for this paper comprise the galvanic skin response; changes in heart rate, blood pressure, respiration, and pupil size; suppression of barpressing/licking; nictitating membrane extension; eyelid closure; and leg or tail flexion. In this section of the paper, we present a brief overview of each of these responses. This is not meant to be an exhaustive review of any system. 


\section{Galvanic Skin Response}

The galvanic skin response (GSR) reflects changes in the activity of sweat glands, with a resultant change in the electrical properties of the skin, such as conductance. According to a review by Fowles (1974), this conclusion is based on the following findings: (1) The basal level of conductance is highest where sweat gland density is greatest; (2) phasic conductance changes are more frequent in these same areas; (3) blocking sweat gland activity eliminates the conductance changes; (4) stimulating the nerves that innervate the glands produces these changes; and (5) peripheral nerve section or sympathetic ganglionectomy eliminates sweat gland activity, decreases the basal conductance level, and abolishes the conductance changes.

In research done with humans, the GSR is commonly recorded from the palm of the hand, the sole of the foot, or the distal and middle phalanges of the fingers (Grings, 1974). With animals, the GSR is recorded from the pads of the feet (see, e.g., Holdstock \& Schwartzbaum, 1965, who used this procedure with rats). The majority of GSR conditioning studies have been done with humans.

GSR conditioning has been questioned but found to be associative. For example, Stewart, Stern, Winokur, and Fredman (1961) suggested that in previous examinations of conditioned GSR, researchers may actually have studied sensitization effects. This conclusion was based on a list of criteria for defining a "conditioned anticipatory response," which included the stipulation that the response's latency be outside the latency range of the "unconditioned response" to the conditioned stimulus (CS). The importance of controls for nonassociative factors was emphasized by Lockhart and Grings (1963). Subsequently, McDonald and Johnson (1965) found that conditioning developed with pairing but not without pairing - that is, in a sensitization control group.

\section{Heart Rate and Blood Pressure}

In this section, we briefly review CRs of heart rate and blood pressure, which are related but separable. Both are associative, as indicated by the use of sensitization controls or discrimination training paradigms, but there are some unresolved issues. For example, a review of visceral and autonomic learning (Harris \& Brady, 1974) revealed that cardiac CRs may consist of either increases (tachycardia) or decreases (bradycardia) in heart rate; moreover, these different forms of the CR have been found by different investigators using the same procedures (e.g., with rats, see Fehr \& Stern, 1965, for acceleration, and Holdstock \& Schwartzbaum, 1965, for deceleration), and they have even been found within training groups in which subjects apparently received identical procedures.

For example, Gantt (1960) reported that in both humans and dogs the CR usually is tachycardia, with a minority of subjects developing a bradycardia CR. He found that within subjects, whatever the direction of the cardiac component of the orienting response, the subsequent cardiac CR was in the same direction, suggesting an individual difference factor. Soltysik, Wolfe, Garcia-Sanchez, and Nicholas (1982) reported that cats which developed conditioned tachycardia also later developed a leg flexion CR; those with a bradycardia CR crouched or were motionless. Thus, the direction of the CR may depend on the individual subject's mode of dealing with anticipatory fear.

The intensity of the unconditioned stimulus (US) appears not to explain CR direction (Fitzgerald \& Teyler, 1970), but restraint and movement appear to be relevant variables. Teyler (1971) used two degrees of restraint (unrestrained or restrained) and two US locations (chest or tail) in rats. No consistent cardiac CR occurred in the unrestrained footshock groups, but the three other groups demonstrated bradycardia. Only the unrestrained footshock group showed escape type movements, suggesting that these may mask an underlying bradycardia CR. Stronger evidence that tachycardia CRs in rats appear to be associated with body movements was provided by Martin and Fitzgerald (1980), who used a discrimination paradigm. They reported bradycardia CRs in restrained rats and tachycardia CRs in unrestrained animals; the latter also developed conditioned body movements.

Iwata and LeDoux (1988) have pointed out that the basal heart rate of restrained rats is higher than that of unrestrained animals. Furthermore, studies in which the subjects have been restrained have tended to result in a bradycardia $\mathrm{CR}$, whereas those done with freely moving animals have yielded tachycardia CRs. Thus, consistent bradycardia CRs may best be observed when basal heart rate is elevated.

Bradycardia CRs also develop in rabbits (Yehle, Dauth, and Schneiderman, 1967), guinea pigs (Anderson, 1972; Edeline \& Weinberger, 1991a, 1991b, 1992), and lizards (Davidson \& Richardson, 1970). Conditioned tachycardia is found in the dog (Gantt, 1960; Fitzgerald 1966) and the pigeon (Cohen \& Durkovic, 1966). However, in all of these cases, the subjects were restrained, indicating that restraint does not preclude tachycardia CRs and suggesting a difference in the cardiovascular response of dogs and birds in comparison with other species.

Pharmacological studies have implicated vagal activity in cardiac CRs (e.g., Dykman \& Gantt, 1959; Fitzgerald, Martin, \& O'Brien, 1973). In a review of the literature, Cohen and Randall (1984) concluded that the vagal influence is more important in conditioned bradycardia and that sympathetic control is more important for conditioned tachycardia. Whichever the direction of the response, the shortest latency change is vagal, and the changes seen early in training seem to have more of a sympathetic component, with the responses later in training being mediated by either type of innervation.

Obrist (see, e.g., Obrist, Sutterer, \& Howard, 1972) has argued that cardiac CRs are very much related to somatic responses, and that there is no evidence that heart conditioned changes are reflections of anything else, such as emotional responses. Cardiac CRs are not artifacts of movements, because they develop at a normal rate with subjects under neuromuscular blockade (Black, 1965). 
However, according to Obrist et al. (1972), this does not eliminate the possibility that heart rate changes are reflections of central nervous system processes that prepare the animal for somatic responses. This is beyond the scope of the present review. The two main points here are (1) that heart rate is a commonly recorded response in conditioning studies, although the direction of the response varies, and (2) that heart rate CRs do not simply reflect feedback from somatic responses.

Respiration, which will be covered separately, does affect heart rate. Huttenlocher and Westcott (1957) demonstrated that varying the speed or form of the respiration (such as different types of gasps) causes changes in heart rate. Clynes (1960) found that biphasic reflexes (acceleration and then deceleration) occur with both inspiration and expiration. Westcott (1959, cited in Shearn, 1961) controlled for respiration effects during conditioning by having the subjects breathe in time to a metronome; a conditioned tachycardia was demonstrated, thus indicating that cardiac responses are not simply the result of respiratory rate changes. Black's (1965) previously cited studies with paralyzed dogs can be considered as controlling for respiration effects, because the animals were artificially ventilated. Thus, although the two systems are interrelated, heart rate conditioning can be distinguished from respiration effects.

Cardiovascular CRs also include changes in blood pressure. Yehle et al. (1967), working with both paralyzed and nondrugged rabbits, found a conditioned increase in blood pressure. Because the heart rate response was a decrease, they concluded that this was a compensatory mechanism for the arterial blood pressure increase, acting via a vagal influence. However, $5 \%$ of the blood pressure responses occurred in the absence of a heart rate deceleration, and $16 \%$ of the heart rate decreases appeared with no blood pressure increases. Hoffman and Fitzgerald (1978) found both the cardiac rate and the arterial blood pressure changes to an aversive CR to be decreases; this would seem to rule out an explanation made purely in terms of compensation. In addition, they used two different USs-ammonia fumes or shock to the chest-and found that whereas the heart rate CRs were greater when the ammonia fume US was used, the blood pressure CRs were the same regardless of the US. Earlier, Schneiderman et al. (1969) used both alpha-adrenergic and cholinergic blockade in a discrimination classical conditioning paradigm with rabbits; they found cardiac CRs in the absence of blood pressure changes, but also suggested that the compensatory vagal reflex may play a role in the elaboration of the cardiac response.

Blood pressure CRs have been demonstrated repeatedly. The CR is seen to be a change in blood pressure; this change consists largely in an increase that (1) has a pattern similar to but significantly greater in magnitude than that of the blood pressure orienting response, and (2) is definitely associative, as has been revealed by compari- sons with sensitization and other control groups (e.g., Iwata \& LeDoux, 1988).

In summary, three main points can be drawn from this overview of cardiovascular conditioned responses: (1) The direction of the cardiac CR is likely to be affected by the degree of restraint or movement or both; (2) conditioned changes in heart rate do not occur in a "vacuum," but are integrated with other components, such as blood pressure, and with other systems, such as the respiratory system; and (3) the effects of conditioning on one component can be isolated from the effects on another component. Shearn (1961) has noted that whether the heart or another system actually "learns" may be a matter of degree, because, as we have noted, it is unlikely that heart rate is completely free from the influence of other systems.

\section{Pupil}

In a 1916 paper (from a speech given to the American Psychological Association) in which Watson explained why the conditioned reflex was the best method for studying behavior in animals and humans, one reflex that he found to be inappropriate for such studies was that of the pupil. Watson described attempts to condition pupillary constriction in humans by using a strong light as the US; the results were inconsistent. Voigt (1968) has reviewed the history of pupillary conditioning for the 50 years following Watson's attempt. Two factors seem to explain failures to obtain pupillary conditioning: an insufficient US, and subjectivity in pupil measurements.

Electric shock is far superior to changes in illumination as a US. For example, Gerall and Obrist (1962) demonstrated no conditioning of a pupillary dilation with light offset as the US but good conditioning with light offset and electric shock as the US. However, light offset is not required for the establishment of a pupillary dilation CR. Weinberger and colleagues have done several studies with cats, in which they have demonstrated conditioned pupil dilations with mild shock as the US (Oleson, Westenberg, \& Weinberger, 1972; see Weinberger, 1982, and Weinberger, Diamond, \& McKenna, 1984, for reviews). In these studies, an infrared pupillometer was used to measure the diameter of the pupil and its responses objectively.

The iris muscles comprise the sphincter pupillae, which constrict the pupil, and the dilator pupillae, which dilate it. Both are doubly innervated by the sympathetic (adrenergic) and parasympathetic (cholinergic) systems (reviewed in Lowenstein \& Loewenfeld, 1969). Spontaneous and evoked pupillary dilations appear to occur through initial inhibition of parasympathetic activity followed by excitation of sympathetic afferents (Ashe \& Cooper, 1978). The major component of the conditioned pupil response seems to occur via inhibition of the parasympathetic system, because CRs can be found when the iris is sympathetically denervated (Ashe, Cooper, \& Weinberger, 1978b). 


\section{Respiration}

Classical conditioning of respiration was reported by Watson (1916) in humans and birds. Since then, various types of conditioned respiratory responses have been found: rate increases in pigeons (Durkovic \& Cohen, 1969) and rabbits (Yehle et al., 1967), rate decreases in goldfish (Wolach, Breuning, Roccaforte, \& Solhkhan, 1977), and "sharp inspirations" in rats (Kappauf \& Schlosberg, 1937). Typical ways of measuring respiration rate consist of using a thermistor to measure expired air temperature, or of using a pneumograph around the thorax. Because there are various forms of changes in respiration (e.g., increases or decreases in rate and/or amplitude), respiration CRs may not be as easy to quantify as are heart rate changes or other CRs. However, Soltysik, Nicholas, and Wilson (1984) found that the conditioned respiration response is much less variable among individual cats than is the heart rate response, and that it consists of an increase in rate and decrease in amplitude. The responses are sometimes complex. For example, Horton (1933) found that in the guinea pig, the CR was initially an increase in respiration rate along with a startle response. Later in training, the response consisted of a decrease in rate and amplitude.

The respiratory rhythm is controlled by the medulla; the pons mediates stability and coordination under different conditions. The brain centers receive information from various receptors. The lungs contain stretch receptors, and there are chemical receptors in the paraganglia derived from the parasympathetic system and in the brainstem (the chemoreceptors monitor changes in blood gas levels and blood $\mathrm{pH}$ ) (Thews \& Vaupel, 1985). The brain respiration centers also receive input from the cortex, hypothalamus, and reticular formation (Stein \& Luparello, 1967). In addition to lung inflation and deflation and chemical changes, other factors that can influence the rate and depth of respiration include emotions, sleep, lung irritants, changes in temperature and light, and speech requirements. Neurons in the medullary centers integrate all of these influences (Eckert \& Randall, 1978).

\section{Conditioned Suppression}

Estes and Skinner (1941) first used conditioned suppression to measure the magnitude of the emotional state during anticipation of an aversive stimulus. They demonstrated that if a tone is paired with a footshock while a rat is barpressing for food, the tone will soon come to suppress the barpressing. The procedure has since been used widely, with lick suppression of water-deprived animals sometimes substituting for barpressing. The procedure used by Estes and Skinner is called conditioning on the baseline, because the CS-US pairings were done against a baseline responding of ongoing pressing. Often, the conditioning phase is done with the bar removed; this is the off-baseline procedure.

The conditioned suppression paradigm is thus used as an index of conditioning to a CS, although the exact behavioral responses are not recorded. Rats usually freeze in response to an aversive CS, which would account for suppression. Whereas conditioning observed in other response systems covered here is measured by changes in some specified effector-a decrease in heart rate or a blink of an eyelid, for example - conditioned suppression is limited to the effects of a CS on performance of a learned instrumental response. The effect of a CS on instrumental responding was reviewed by Rescorla and Solomon (1967), who explained such classical-instrumental interactions as being due to emotional reactions to previously neutral CSs.

\section{Nictitating Membrane}

The nictitating membrane (NM), the "third eyelid," is found in dogs, cats, monkeys, and rabbits, and is extended over the animal's eye presumably to serve a protective function. Gormezano, Schneiderman, Deaux, and Fuentes (1962) first demonstrated the NM CR in rabbits, and a summary of the first 20 years of this research is available (Gormezano, Kehoe, \& Marshall, 1983). The NM preparation has been used for behavioral studies by many investigators and has become the most extensively used model for neurobiological studies of associative learning of discrete skeletal CRs in vertebrates.

In the initial studies, a puff of air to the eye was used as the US, but shock to the area of the eye is also widely used (Gormezano et al., 1983). The response in the rabbit preparation is usually detected by a thread attached to the membrane and leading to a potentiometer (for example, in Gormezano et al., 1962). NM conditioning has also been obtained in other animals, such as toads (Yaremko, Boice, \& Thompson, 1969) and sharks (Gruber $\&$ Schneiderman, 1975). Its wide use indicates its effectiveness in the investigation of various phenomena in classical conditioning (Gormezano, Prokasy, \& Thompson, 1987).

The mechanism of NM extension has been studied in the rabbit. Originally it was thought to be controlled by the abducens nucleus (Cegavske, Thompson, Patterson, \& Gormezano, 1976); it now appears that the accessory abducens nucleus is more important (Cegavske, Harrison, \& Torigoe, 1987). The retraction of the NM is passive, resulting from eyeball retraction by the retractor bulbi muscles.

\section{Eyelid}

Early work on the conditioning of the rabbit outer eyelid was established by Gormezano and colleagues (Schneiderman, Fuentes, \& Gormezano, 1962). The US and the measurement techniques employed are very similar to those used for the NM responses, but the EMG of relevant muscles is often recorded instead. McCormick, Lavond, and Thompson (1982) recorded NM responses (via a potentiometer) and eyelid responses (by recording from the relevant muscles) simultaneously. Blinks of the eyelid almost always accompanied spontaneous NM extensions, but NM extensions did not always accompany spontaneous eyelid blinks. However, the two responses were 
highly correlated during learning. This correlation obtained in both the decreases in latency and the increases in amplitude of the responses.

Eyelid conditioning has also been obtained in dogs (Vardaris \& Fitzgerald, 1969) and, with a glabellar tap as the US, in cats (Woody, Yarowsky, Owens, BlackCleworth, \& Crow, 1974).

\section{Leg/Tail Flexion}

The movement of a limb or of the tail has been measured during Pavlovian defensive conditioning. The flexion conditioning procedure involves pairing a CS with a shock delivered to either the leg or the tail. The flexions have been recorded with various methods, such as the use of a thread attached to a transducer (Plumer, Siegel, \& Cicala, 1973).

Leg flexion conditioning has been accomplished with rats (Ginn, Valentine, \& Powell, 1983), cats (O'Brien \& Packham, 1973), dogs (Barnes, 1956), and lizards (Davidson \& Richardson, 1970). Tail flexion CRs have been observed in rats (Chacto \& Lubow, 1967; Miller, Greco, \& Vigorito, 1981). Konorski (1967) has pointed out that anticipatory general motor restlessness develops as a conditioned defensive behavior within a small number of trials. This behavior could produce apparent limb or tail flexion CRs, as will be discussed in the survey results section.

\section{SURVEY OF THE LITERATURE}

\section{Location of Papers}

\section{Domain of the Survey}

The papers in the survey were located through the use of several different sources. One of these was a Dialog search of the Psych information database, using the items "animal" and "classical conditioning" as the key words. In addition, the Psychological Abstracts indexes were manually scanned for the period 1984-1985, and the cumulative indexes were scanned for the period 1927-1983; the heading "classical conditioning," as well as headings for the various response systems (if there were such headings) were examined. Some of the papers were located through use of the reference sections in other papers. Each paper was read to determine whether its data met the criteria necessary to measure acquisition of the $C R$ in question.

\section{Criteria for Selecting Papers}

The criteria used to select papers are explained below.

English language. Papers in foreign languages were omitted, owing to the difficulty in extracting the relevant information.

Nonhuman subjects. These were selected in order to avoid variables such as experimenter instructions. However, most of the studies summarized for GSR conditioning had human subjects. This was necessary, owing to the paucity of such experiments on nonhumans.

"Normal" environmental stimuli that engage exteroceptors. The sample was restricted to studies in which both the CS and the US were applied to normal sensory receptors. This eliminated the use of brain stimulation as a stimulus. Also, comparisons between papers are likely to be more valid if the analysis is restricted to the use of normal sensory stimuli. For instance, in an NM study by Patterson (1970), the CS was stimulation of the inferior colliculus. Although conditioning was obtained with an interstimulus interval (ISI) of $50 \mathrm{msec}$, Smith, Coleman, and Gormezano (1969), in an earlier NM study, failed to get conditioning with this same ISI using a tone CS. In addition, it is difficult to interpret what is occurring when brain stimulation is performed, and for a survey such as this, it is important to obtain "normal" data first.

No discrimination tasks. Data from discrimination paradigms were not used to obtain information on acquisition rate, with the exception noted below, because they could not be combined with data obtained from simple conditioning paradigms. This is because the rate of development of a CR can be affected by the presence of a nonreinforced stimulus on some trials (Mackintosh, 1974). An exception to this criterion was made if conditioning in the experiment started with a CS + only, and if the CS was added in a second phase (e.g., Ryugo and Weinberger, 1978); in these cases, data from the acquisition phase were used. Studies in which discrimination learning was examined in multiple response systems simultaneously within subjects are considered separately.

Clear presentation of acquisition data. Acquisition data were obtained from published graphs of performance versus trial blocks, because tables of acquisition data are seldom published. It was therefore necessary for the trial graphs to be presented in a manner that was sufficiently clear to determine the trial or trial block during which the first consistent CRs appeared.

Data presented in blocks of no more than about 50-60 trials. It is customary to plot acquisition data in blocks of trials. This procedure yields a smoothing function and also allows a more efficient way to present data when the learning occurs over many trials. Papers in which the data were graphed in blocks of more than about 50-60 trials were generally avoided, because if learning was obtained in the first block, it would be impossible to make a very accurate determination of the trial of the first CR. However, if no learning was observed in the first block, the data could be included because trials to the first consistent $\mathrm{CR}$ could be established as at least greater than the number of trials in the first block. For example, an eyelid experiment of Gutmann, Brozek, and Bures (1972) had 100-trial blocks, but without clear learning until the second (with an auditory CS) or fourth (visual CS) block.

Ten to fifteen papers for each response system. This goal was set to obtain a sufficient sample, without requiring complete inclusion of every publication in the relevant conditioning literature. However, the minimum number was not met in some instances: for blood pressure, only 2 papers met the criteria outlined above; for respiration, there were 7; and for limb/tail flexion, there were also 7. For GSR, heart rate, pupil, conditioned suppression, eyelid, and nictitating membrane, the goal of $10-15$ papers 
was met. However, 8 out of 10 of the GSR papers were reports on experiments with human subjects.

For conditioned suppression studies, only those with an on-baseline procedure were summarized. Because the onbaseline procedure in conditioned suppression involves giving the CS-US trials while the animal is performing some task (as opposed to not testing the effects of the CS on performance until after several pairings), it was thought that this procedure was better for determining the first CR. Sometimes the data in such cases were presented for single trials.

Pretreatments prior to conditioning training were eliminated. If data were subject to influence by pretreatments, such as extensive CS preexposure to induce latent inhibition, they were not used in the survey.

\section{Multiple Data Sets Within a Publication}

Because of the nature of some of the experiments, several sets of data could sometimes be obtained from the same paper. An example is a publication in which the effects of shock duration on conditioned suppression were examined (Riess \& Farrar, 1973); each group of subjects, with a different US duration, was used for the present analysis. In addition, if several experiments were done, each with a control group that demonstrated acquisition, then each control group's data were used.

\section{Information Obtained From Each Paper}

The following information was recorded from each paper reviewed. Only those meeting the criteria listed above were included in the actual literature survey.

1. Citation

2. Subject (species)

3. Preparation (restrained, paralyzed, etc.)

4. Behavioral measure (heart rate, eyelid, etc.)

5. CS parameters (type, intensity, duration, etc.)

6. US parameters (type, intensity, duration, etc.)

7. CS-US relation (trace or delay)

8. CS-US interval

9. Pretreatment

10. Intertrial interval (ITI)

11. Number of conditioning trials per day

12. Number of test trials per session, if any

13. Nature of conditional response (heart rate increase, blink, etc.)

14. Number of trials to first consistent $C R$

15. Number of trials to experimenter's criterion

16. Number of trials to asymptotic performance

17. Number of trials per block in acquisition plots

18. Presence or absence of control groups for nonassociative effects

\section{Determining the Acquisition Values}

All three of the recorded acquisition values (first consistent CR, experimenter's criterion, and asymptotic performance) were recorded in terms of the trial block. For instance, if the first CR occurred in the third 10-trial block of trials, this would be recorded as Trials 21-30. A CR cannot, of course, be observed to the first CS presentation, because the US has not been previously paired with it. Thus, in the example just given, if learning occurred in the first block, it would be recorded as $2-10$ and not 1-10.

The first consistent $C R$ is defined as the first trial block in which the response was above the control baseline (e.g., sensitization or pseudoconditioning groups). In order to be considered consistent, the $\mathrm{CR}$ had to remain above this baseline.

Control data were often not available. In their absence, it was difficult to determine the first CR. Sometimes responses during the first block or two of trials were at or near the zero response level, making the task somewhat easier. But, particularly with eyelid and NM data, such was not often the case. For such data, a sensitization baseline of approximately $10 \%$ was assumed, based largely on published control group data. This $10 \%$ value might be considered too large, providing an overestimate of trials to the first CR. However, review of data with this potential problem, using the lowest possible trial number and thus risking errors of commission, had no effect on the results of the statistical analyses.

For graphical and statistical purposes, we used the value of the midpoint of the trial block in which the first $C R$ occurred. For example, if the first $C R$ appeared in the first block, and the trials were in five-trial blocks, then the value used for statistical purposes was 3.5 (midway between 2 and 5).

Although the "number of trials to criterion" and the "number of trials to asymptote" were recorded, no analyses of these are presented here. Neither is an optimal measure for comparing learning rates because the criteria, when stated, varied widely among authors. The "number of trials to asymptote" proved not to be useful, because asymptotic data were not sufficiently reported.

\section{RESULTS OF THE SURVEY}

All of the data included in the survey are listed in Appendix $A$, with a separate table for each response system (Tables A1-A9).

\section{Number of Trials to First CR}

The mean numbers of trials to the first CR across the various types of CRs are presented in Figure 1. The data are on a log scale, and they are arranged from lowest to highest values (fastest to slowest acquisition). They are discussed in the same order here.

\section{Galvanic Skin Response}

As explained earlier, the majority of the data summarized here are from human subjects. A comparison of the data from the human GSR studies with those from studies done with rats (Holdstock \& Schwartzbaum, 1965) and cats (Van Twyver \& King, 1969) reveals a similarity in number of trials to the first CR; for all three species, this 


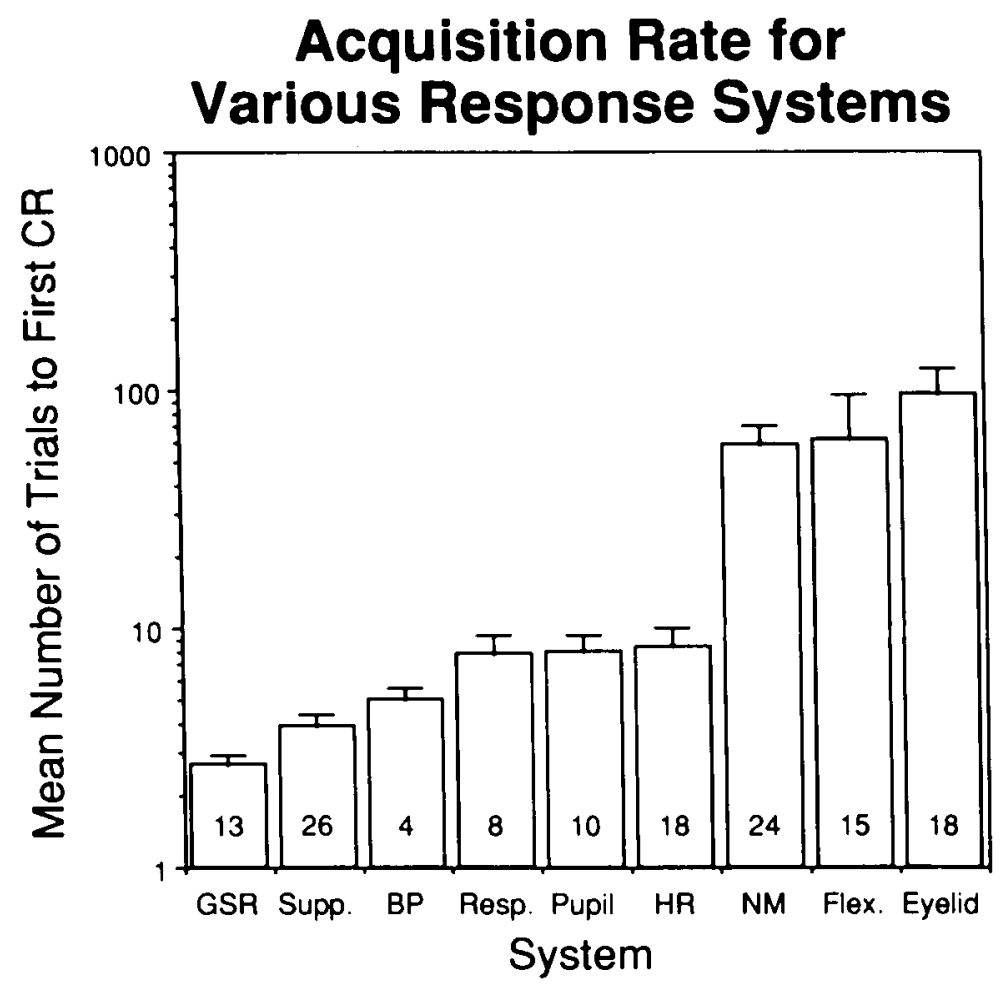

Figure 1. Number of trials to first conditioned response (CR) by response system. The mean number of trials to the first $C R$ is depicted on a log scale. There is a clear bimodal distribution of learning rates, with the first six responses forming one group ("fast" CRs) and the last three responses forming a second group ("slow" CRs). The error bars represent standard error of the mean. The numbers within each bar in this and all subsequent figures are the number of groups represented. GSR, galvanic skin response; Supp., conditioned suppression; BP, blood pressure; Resp., respiration; HR, heart rate; NM, nictitating membrane; Flex., nexion.

response occurred within the first six trials; the mean was $2.7( \pm 0.23$ SEM $)$.

\section{Conditioned Suppression}

Conditioned suppression, along with the pupil, had the highest degree of homogeneity with regard to species; here, all of the subjects were rats. The most common CS was noise; tone seemed to be more prevalent for the other responses. There was little variation in number of trials to the first $\mathrm{CR}(M=3.9 \pm 0.43)$.

\section{Blood Pressure}

Only two papers met the criteria; they yielded four sets of data. Yehle et al. (1967) used a restrained and a paralyzed group, and Hoffman and Fitzgerald (1978) used two different USs (shock and ammonia fumes). Still, this response system is the most underrepresented of any of the nine. The two papers were consistent in the rate of acquisition: in one, the first CR was reported as occurring in Trials 2-10 (Yehle et al., 1967); in the other, in Trials 2-6 (Hoffman \& Fitzgerald, 1978); the mean was 5.0士 0.58 trials.

\section{Respiration}

Eight groups from seven papers are summarized; in four of the groups, and in three of the papers, the subjects were fish (Davis \& Holmes, 1971; Wolach et al., 1977; Woodard, 1971). Fish seem to achieve the first $C R$ in about the same number of trials as do mammals or birds. The mean number of trials for all of the eight groups was $7.8 \pm 1.6$ trials.

\section{Pupil}

All of the pupil studies are from the cat. Also, all but one of the studies are from the Weinberger laboratory; this reflects the fact that the pupil is rarely used as a response index in animal classical conditioning. The mean number of trials to the first CR was 7.9 \pm 1.5 .

\section{Heart Rate}

This response system had the widest range of species represented: rat, rabbit, dog, pigeon, guinea pig, and lizard. The mean and standard error $(8.4 \pm 1.7)$ would have been smaller if not for the fact that in three of the pigeon papers (Cohen \& Durkovic, 1966; Cohen \& Pitts, 1968; 
Durkovic \& Cohen, 1969), unusually large (for heart rate conditioning) trial blocks were reported-20 trials/block.

\section{Nictitating Membrane}

Nictitating membrane is represented by 24 groups of animals. There were wide ranges of values for the first CR, from 2-30 in the toad (Yaremko et al., 1969) to 201-300 in a rabbit study (Graves \& Solomon, 1985). The mean value was $59.2 \pm 11.8$.

\section{Limb/Tail Flexion}

The mean value for trials to the first $\mathrm{CR}$ was $62.2 \pm 32.9$. This response showed the largest standard error. The range of values was from a low of 2-4 trials (Barnes, 1956) to a high of 401-500 trials (Miller et al., 1981). This wide range, unique among the response systems surveyed, merits detailed consideration. Limb and tail flexion will be discussed separately.

Limb flexion. The extremely large range of trials to the first CR suggests problems in underestimating or overestimating the rate of conditioning. With respect to extremely low values, there is a potential problem in distinguishing specific leg flexion from general motor restlessness. Very rapid development of conditioned leg flexion in the dog (Barnes, 1956) was found in eight groups. A $2 \times 4$ design was used in this experiment; there were two values for CS intensity and 4 different degrees of the CS overlapping the US. All eight groups displayed the first CR in 2-16 trials. A flexion response was defined as a femoral rotation of $5^{\circ}$ or more. This seems to be a very lenient criterion. Furthermore, there was no control for nonassociative effects. Although the response did increase in frequency over trials, it is not clear how much of this was an actual flexion as opposed to leg movements due to conditioned motor restlessness, which conditions rapidly (Konorski, 1967).

Another rapidly acquired CR, in the lizard (Davidson \& Richardson, 1970), suffers from the same two problems as does the Barnes (1956) experiment: there is no control for sensitization effects, and the definition of a flexion CR appears too lenient-" "movement of the leg in any direction." Still, the experimenters' criterion of 80-100\% CR frequency for 3 consecutive days was achieved in 150 trials, compared to less than 20 trials for respiration and 110 trials for pulse rate.

Tail flexion. The two tail flexion studies (both done with rats) resulted in extremely different numbers of trials to the first CR. Chacto and Lubow (1967) reported 2-50 trials, and Miller et al. (1981), 401-500 trials. Both of these experiments had either an unpaired or a random control group. It is difficult to determine from the papers whether or not one of the two tail movement monitoring systems was more sensitive than the other. The Chacto and Lubow study might have detected tail movements secondary to body restlessness.

In conclusion, the flexion data are problematic. Although many studies that could not be included in this survey have definitely established the flexion response as a genuine
CR (Mackintosh, 1974), some of the flexion papers in this survey may include overestimates of acquisition rate (underestimates of trial to the first CR) due to a failure to distinguish flexion from general body movements.

\section{Eyelid}

Data from 18 groups are included in the survey, representing nine publications. The mean number of trials to the first $C R$ is $95.2 \pm 28.6$. This large standard error reflects the large range of values, from a low of 2-20 trials (Vardaris \& Fitzgerald, 1969, for the dog) to a high of 301-400 trials (Gutmann et al., 1972).

\section{"Fast" and "Slow" Conditioned Response Systems}

The data in Figure 1 fall into a bimodal distribution, with GSR, conditioned suppression, blood pressure, respiration, pupil, and heart rate all with a mean number of trials to the first CR of less than 10, and with NM, flexion, and eyelid all with values between 50 and 100 . Thus, there is a group of rapidly acquired ("fast") and a group of slowly acquired CRs.

The distinction seems to be between CRs that are specific to the US location (the "slow" CRs) and those that are not thus specific (the "fast" CRs). This will be discussed more completely later. For statistical purposes, the "slow" CRs were combined into one group and the "fast" CRs into another group. The combined group data are shown in Figure 2. There is a clear distinction between the two types of CRs; the difference is statistically significant ("fast" $=5.7 \pm 0.53$, "slow" $=71.3 \pm 13.4$, $p \leq .0001$, two-tailed unpaired $t$ test).

Thus, the studies surveyed in this review do support the notion of two classes of CRs with respect to the rate of CR development. In the next section, we will consider possible explanations of this distinction other than the two types of response system. For brevity of expression, the response systems are hereafter referred to as "fast" and "slow"; no surplus meaning is intended beyond the use of these terms to refer to the six response systems, all of which had mean trials to first CR value of less than 10 trials (range $=2.7-8.4$ ), and the three response systems, all of which had a mean value greater than 50 trials (range $=59.2-95.2){ }^{1}$

\section{Other Variables That Might Account For Differences in Learning Rate}

The response system measured is not necessarily the only difference in the conditioning procedures between the two groups in Figure 2. Four variables that affect learning rate are considered here (see Mackintosh, 1974, for a review): CS intensity, US intensity, ISI, and ITI. The data for these variables are shown in Figure 3.

\section{CS Intensity}

The rate of acquisition could be affected by CS intensity. We analyzed this parameter in the case of auditory stimuli. Figure $3 \mathrm{~A}$ depicts the CS intensity data for the 


\section{Acquisition Rate for Fast and Slow Conditioned Reponses}

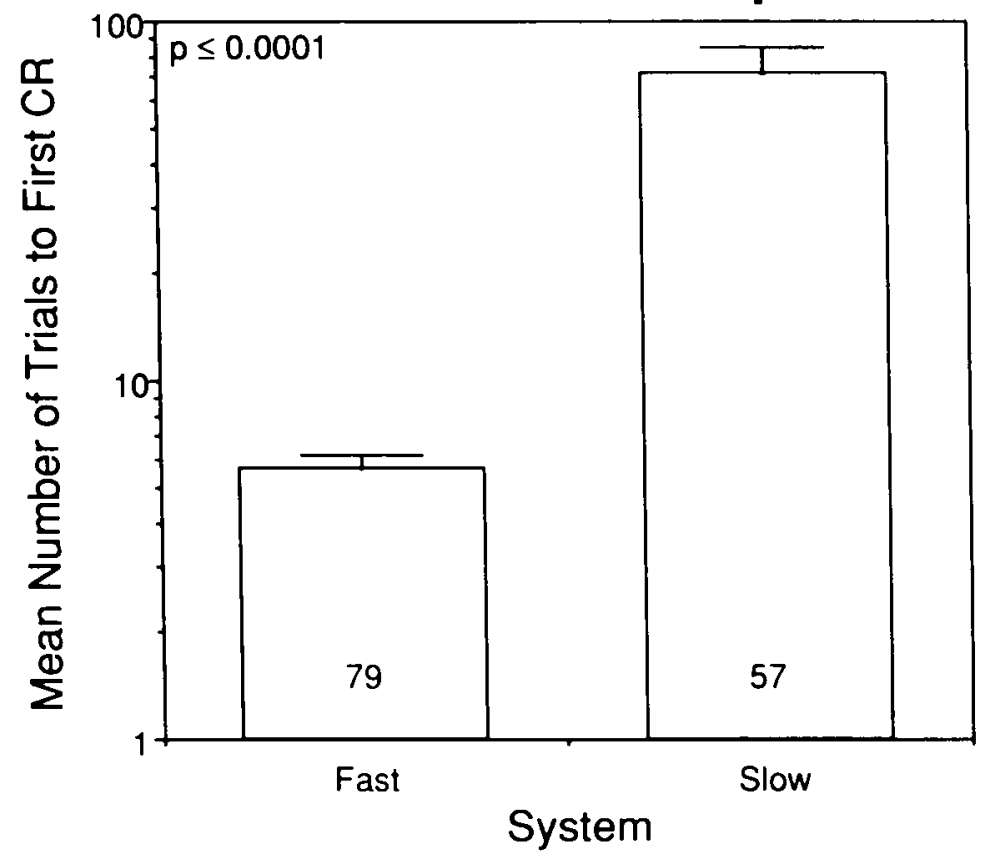

Figure 2. Number of trials to first conditioned response (CR) by type of response system. The mean number of trials to the first $\mathrm{CR}$ is depicted on a $\log$ scale. The statistical test for all data in this review was the two-tailed, unpaired t test. The difference in learning rate between the two groups of CRs, which was suggested in Figure 1, is significant. The error bars represent standard error of the mean.

fast and slow CR groups. The mean intensity was not statistically different [fast $(45)=74.7 \mathrm{~dB} \pm 15.8 S D$; slow $(43)=79.4 \mathrm{~dB} \pm 9.6 S D, p>.05]$. Thus, differences in the CS intensity cannot account for the fast-slow distinction.

\section{US Intensity}

The intensity of the US is obviously a major parameter in conditioning. We analyzed US intensity for electrical shock between the fast and slow groups. The shock intensities are expressed in terms of coulombs $(C)$ rather than amperes; the former unit includes current duration, which contributes to the aversiveness of the US. Figure 3B presents the mean US intensities used for the two groups of CRs. The graph, which is on a log scale, shows that the mean US in the fast group $(n=64)(3.7 \mathrm{mC} \pm 7.9 S D)$ was higher than the mean value for the slow group ( $n=$ 38) $(0.39 \mathrm{mC} \pm 0.87 S D)$. This was statistically significant $(p \leq .02)$. Thus, the more intense US used in the studies of rapidly acquired CRs might account for the difference in acquisition rate. However, two factors suggest that this is not the case.
First, the fast-slow distinction is still observed when the two types of CRs are measured simultaneously within the same subject, where there is only one US intensity, which is obviously the same for all response systems. These data are presented in Table 1 and will be discussed in a later section.

Second, we used a subset of the data whose means are given in Figure 1 to obtain a set of studies in which the difference in US intensity was eliminated by matching based on US intensity. Data from the two larger groups (slow and fast) were matched so that the USs were $\pm 0.150 \mathrm{mC}$ or less of each other. This resulted in a group of 27 fast CRs (representing 15 conditioned suppression, 4 GSR, 3 heart rate, and 3 respiration groups, as well as 1 blood pressure and 1 pupil group) and 27 slow CRs (with 13 nictitating membrane, 8 eyelid, and 6 flexion groups). (The studies used for the matching are listed in Appendix B). The fast CR group had a US intensity of $0.30 \mathrm{mC}( \pm 0.19 S D)$, and the slow CR group, a US intensity of $0.29 \mathrm{mC}( \pm 0.19 S D)$. (See Figure 4A.) This difference was not significant $(p>0.05)$. Figure 4B shows that when the number of trials to the first $C R$ were 


\section{Variables Which May Affect Rate of Acquisition: Fast and Slow CRs}
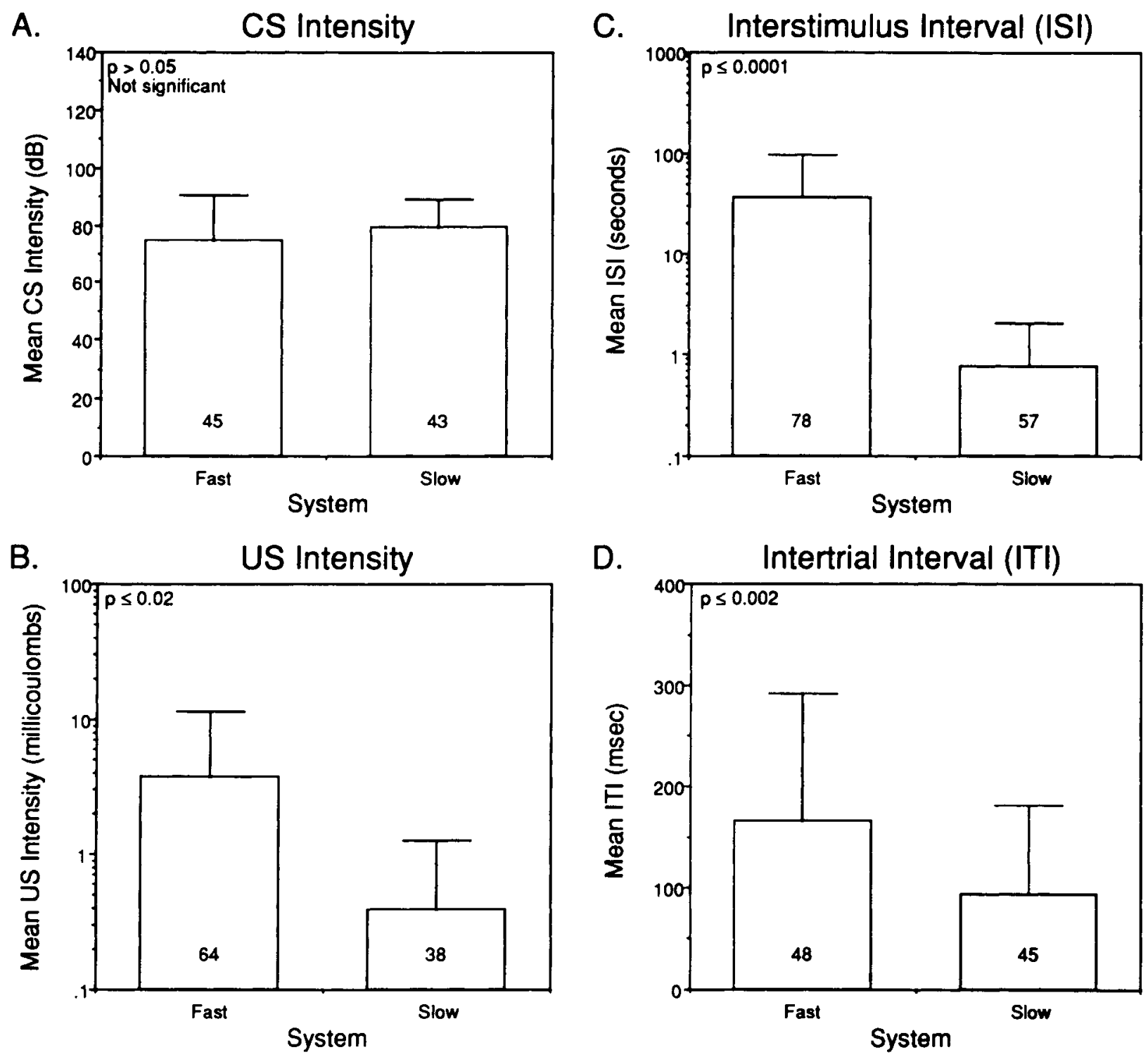

Figure 3. Variables that may affect rate of learning. Mean conditioned stimulus (CS) intensity, unconditioned stimulus (US) intensity, ISI, and ITI are shown for the two types of response systems ("fast" and "slow"). Values in panels B and C are on log scales. Although the differences for US intensity, ISI, and ITI were different between the two groups, they are not likely explanations of the learning rate differences (see text). For all four variables, the error bars represent standard deviations.

determined for the two matched groups, there was still a significant difference $(p \leq .0002)$ between the fast $(4.9 \pm 0.66$ trials $)$ and slow $(82.4 \pm 19.6$ trials $)$ groups. Thus, eliminating the US intensity difference did not eliminate the fast-slow distinction.

\section{Interstimulus Interval}

The ISI (CS-US) can affect the rate of conditioning. The mean ISIs for the two groups of CRs are given in Figure 3C. The ISI is longer for the fast CRs (36.8 $\pm 61.2 \mathrm{sec})$ than for the slow CRs $(0.75 \pm 1.3 \mathrm{sec})$; this is a significant difference ( $p \leq .0001)$. Conditioned suppression studies contribute greatly to this difference because of the very long CS-US intervals $(M=100 \mathrm{sec})$ that are used to assess the suppression of an ongoing operant. However, even if suppression is eliminated from the analysis, the quickly acquired CRs still have longer ISIs ( $M=5.2 \mathrm{sec}$, compared to $0.75 \mathrm{sec}$ for the slow responses; $p \leq .0001$ ). One might argue that the differences in trials to the first CR are attributable to this dif- 


\section{US Intensity: Matching of Fast and Slow Groups}
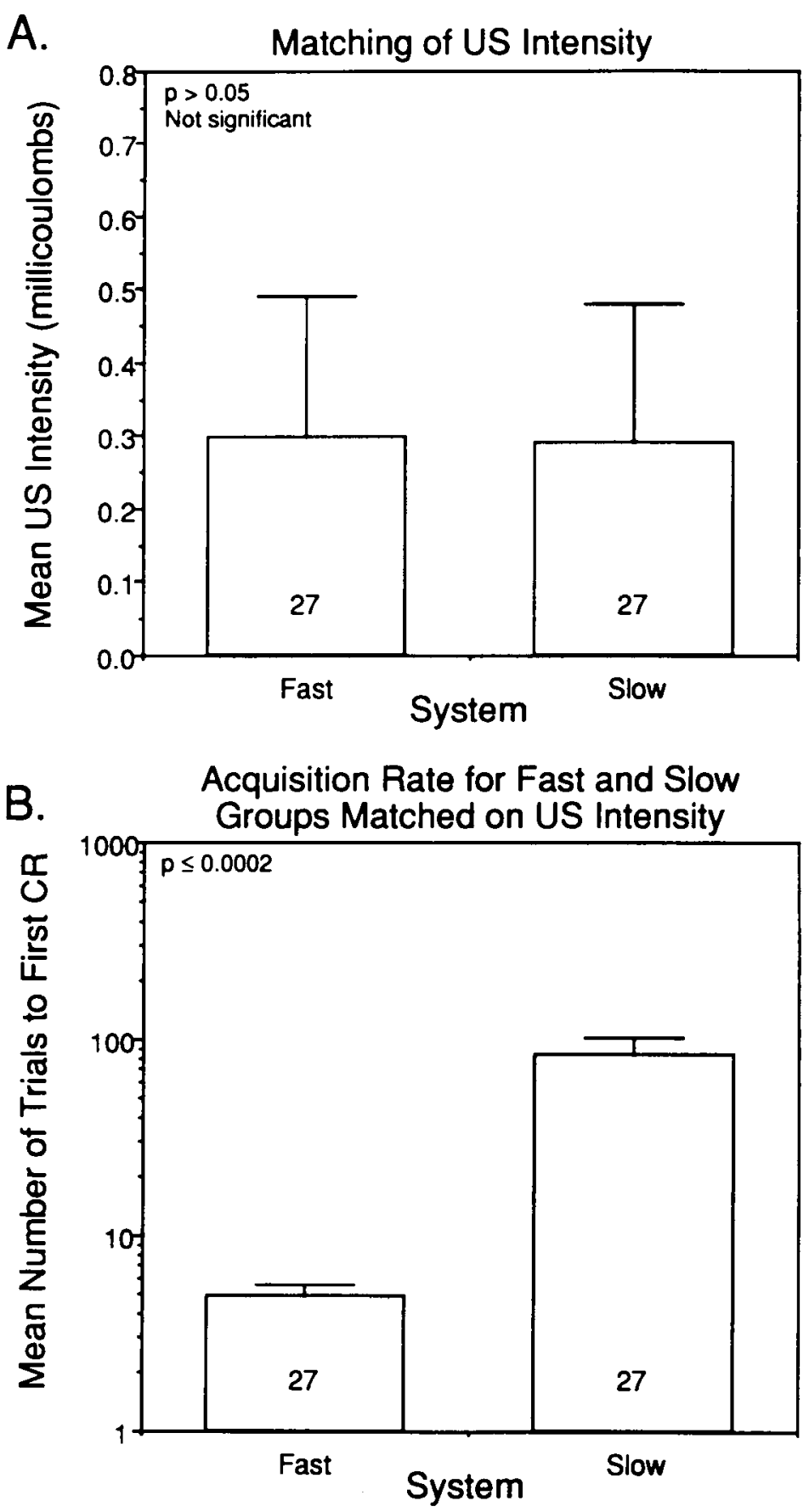

Figure 4. Fast and slow groups matched on unconditioned stimulus (US) intensity. (A) Results on mean US intensity of matching "fast" and "slow" conditioned responses (CRs) on the US intensity (details in text). (B) Effect on the learning rate. Matching on US intensity does not eliminate the learning rate difference. The error bars in panel A represent standard deviations, those in panel B, standard error of the mean. 
ference. If so, it is not obvious why a longer ISI should favor more rapid conditioning.

Matching fast and slow response systems on ISI is not really possible, because not enough studies of the two types of response systems have overlapping ISIs. Undoubtedly, this reflects an extensive literature which demonstrates that various response systems have different optimal ISIs for conditioning (for a review, see Mackintosh, 1974). For example, the use of an ISI greater than $1.0 \mathrm{sec}$ to study NM conditioning makes little sense, because the NM exhibits much worse conditioning at such intervals than it does at fractions of a second. Although not as extensively studied, autonomic responses such as heart rate, blood pressure, and GSR not only are likely to have optimal ISI of several seconds, but in practice require longer ISIs to show full expression during the CS-US interval (but see below: Powell \& Levine-Bryce, 1988). There is no such constraint on NM, eyelid, and flexion responses, all of which reflect the rapid actions of skeletal musculature acting for a brief period. In any event, even if studies could be matched on the basis of ISI, such data would not be illuminating because the ISI selected would likely favor one type of response system over the other.

Although the fast and slow CRs differ significantly on ISI, it is not necessary to conclude that the difference in rates of acquisition is due to the difference in ISI, for two reasons. First, the mean ISIs for the slow and fast response systems are near their optimal values, $(0.75$ and $5.2 \mathrm{sec}$, respectively). Thus, it could be argued that even with the ISI near optimal for a particular system, the slow-fast distinction is still present.

Second, studies with concurrent recording of the NM and heart rate responses (within subjects) show faster acquisition of heart rate than of NM CRs (Table 1 and see below). One particularly relevant study involved the concomitant recording of eyeblink and heart rate, using a short ISI (Powell \& Levine-Bryce, 1988). Whereas an ISI of several seconds is used in most studies of heart rate, in this study the ISI was $0.5 \mathrm{sec}$, and heart rate was assessed on a beat-by-beat basis during the ISI. The authors found that the heart rate $C R$ developed prior to the eyelid $C R$, even with an ISI of $0.5 \mathrm{sec}$, which is near optimal for eyelid conditioning. Overall, then, despite the difference in ISI for rapidly and slowly acquired CRs, the differential rates of conditioning appear to reflect the types of response systems, not merely their ISIs. ${ }^{2}$

\section{Intertrial Interval}

The ITI can affect acquisition rate; longer intervals ("distributed trials") might promote learning, relative to shorter ITIs ("'massed trials") (Mitchell, 1974; Prokasy $\&$ Ebel, 1964). Figure 3D presents the mean ITIs for the fast and slow groups. (Conditioned suppression was dropped from this analysis, because the ITI was often not reported or was $24 \mathrm{~h}$-i.e., $1 \mathrm{trial} /$ day.) The difference in ITIs between the two groups is significant (fast = $166 \pm 126.2 \mathrm{sec}$; slow $=93.9 \pm 87.6 \mathrm{sec}, p \leq .002$ ). This difference probability reflects the fact that some of the fast CRs (such as heart rate) require a longer time to return to baseline after a CR than do the responses such as NM, eyelid, and flexion, which are very brief in duration. In any event, the difference in ITI favors the fast versus the slow CRs, because trials for the former are "ddistributed," relative to the latter ("massed trials"). Thus, the difference in ITI might account for the difference in acquisition rates between the fast and slow CRs.

However, two considerations suggest that the difference in rates of learning is not due to the difference in ITI. First, the fast-slow distinction is present for withinsubject experiments in which a fast and a slow CR are recorded simultaneously and there is only a single ITI. For example, when heart rate and NM are measured together (Table 1), the slow-fast distinction remains; heart rate generally conditions in fewer trials than does the NM.

Second, as in the case of US intensity, we eliminated the difference in ITI by matching studies that were based on this parameter. This yielded 23 fast (blood pressure $=2$, GSR $=7$, heart rate $=2$, pupil $=10$, and respiration $=2$ ) and 15 slow groups (eyelid $=6$, $\mathrm{NM}=9$ ) (see Appendix B). The mean ITIs for these groups were as follows: fast $=73.5 \pm 30.5 \mathrm{sec}$, slow $=$ $90.7 \pm 49.5 \mathrm{sec},(p<.19$, two-tailed unpaired $t$ test). However, the difference in trials to the first $C R$ was still present: fast $=5.5 \pm 3.8 \mathrm{sec}$, slow $=43.7 \pm 32.3 \mathrm{sec}$ $(p<.0001)$. Moreover, seven groups from the slow category had particularly long ITIs; their addition yielded a reversal of the initial ITI relationships, so that there were significantly greater ITIs for the slow versus the fast group: slow $(22)=147.5 \pm 98.3 \mathrm{sec}$, fast $(23)=73.5 \mathrm{sec}$ $(p<.001)$. Yet the difference in mean trials to the first CR was still present: slow $(22)=54.1 \pm 45.5 \mathrm{sec}$, fast $(23)=5.5 \pm 3.8 \mathrm{sec}(p<.0001)$. In summary, differences in mean ITI do not account for the difference in learning rate between the fast and slow response systems.

\section{Multiple Response Systems}

A direct way to compare the learning rates of two systems is to record both simultaneously. A summary of studies in which multiple responses were recorded simultaneously from the same animal is provided in Table 1. Discrimination experiments are included because of the paucity of nondiscrimination multiple response system studies that met the criteria outlined earlier. Moreover, their inclusion produces no problems, because the comparisons are within experiment. In the discrimination studies, the trials to the first CR were determined for the $\mathrm{CS}+$. Because of the mixture of discrimination and nondiscrimination studies, summary statistics were not calculated for these data.

Heart rate was recorded in all the studies. In rows 1-12 (Table 1), one or two additional fast responses were measured. Rows 1 and 2 summarize data from two studies in which conditioned suppression was measured. Both heart rate and conditioned suppression responses occurred within 20 trials. In both cases, the suppression occurred 
Table 1

Multiple Response Systems Recorded Simultaneously During Classical Conditioning

\begin{tabular}{|c|c|c|c|c|c|c|c|c|c|c|}
\hline \multirow[b]{2}{*}{ Row } & \multirow[b]{2}{*}{ Subject } & \multicolumn{7}{|c|}{ Number of Trials Until First CR } & \multirow[b]{2}{*}{ ISI } & \multirow[b]{2}{*}{ Citation } \\
\hline & & Heart Rate & $\begin{array}{l}\text { Conditioned } \\
\text { Suppression }\end{array}$ & GSR & $\begin{array}{c}\text { Blood } \\
\text { Pressure }\end{array}$ & Respiration & Flexion & NM & & \\
\hline 1 & Rat* $^{*}$ & $7-12$ & $2-6$ & & & & & & 90 & Parrish, 1967 \\
\hline 2 & Rat $^{*}$ & $13-16$ & $2-4$ & & & & & & 180 & deToledo \& Black, 1966 \\
\hline 3 & Rat & $2-8$ & & $2-6$ & & & & & 5 & Holdstock \& Schwartzbaum, 1965 \\
\hline 4 & Rat & $2-8$ & & $2-6$ & & & & & 5 & Holdstock \& Schwartzbaum, 1965 \\
\hline 5 & Rabbit $\dagger$ & $2 \cdot 10$ & & & $2-10$ & & & & 4 & Yehle, Dauth, \& Schneiderman, 1967 \\
\hline 6 & Rat & $2-6$ & & & $2-6$ & & & & 6 & Hoffman \& Fitzgerald, 1978 \\
\hline 7 & Rat & $2-6$ & & & 2-6 & & & & 6 & Hoffman \& Fitzgerald, 1978 \\
\hline 8 & Rabbit & $2-10$ & & & $2-10$ & $2-10$ & & & 4 & Yehle, Dauth, \& Schneiderman, 1967 \\
\hline 9 & Pigeon & $2-20$ & & & & $2-20$ & & & 6 & Durkovic \& Cohen, 1969 \\
\hline 10 & Pigeon & $2-20$ & & & & $2-20$ & & & 6 & Cohen \& Durkovic, 1966 \\
\hline 11 & Lizard & $2-10$ & & & & $2-10$ & $2-10$ & & 10 & Davidson \& Richardson, 1970 \\
\hline 12 & Rabbit & $2-24$ & & & & $2-24$ & & $25-48$ & 0.7 & Yehle, 1968 \\
\hline 13 & Rabbit & $2-24$ & & & & & & $25-48$ & 1 & Yehle, Spaulding, \& Lai, 1970 \\
\hline 14 & Rabbit & $2-40$ & & & & & & $41-80$ & 0.75 & VanDercar \& Schneiderman, 1967 \\
\hline 15 & Rabbit & $2-40$ & & & & & & $41-80$ & 2.25 & VanDercar \& Schneiderman, 1967 \\
\hline 16 & Rabbit & $2-40$ & & & & & & $41-80$ & 0.35 & Meredith \& Schneiderman, 1967 \\
\hline 17 & Rabbit & $2-40$ & & & & & & $81-120$ & 1 & Meredith \& Schneiderman, 1967 \\
\hline 18 & Rabbit & $2-40$ & & & & & & $81-120$ & 1 & Meredith \& Schneiderman, 1967 \\
\hline 19 & Rabbit & $41-80$ & & & & & & No $C R$ & 6.75 & VanDercar \& Schneiderman, 1967 \\
\hline 20 & Rabbit & $2-40$ & & & & & & $2-40$ & 0.25 & VanDercar \& Schneiderman, 1967 \\
\hline 21 & Rabbit & $2-40$ & & & & & & $2-40$ & 0.35 & Meredith \& Schneiderman, 1967 \\
\hline
\end{tabular}

Note-CR, conditioned response; GSR, galvanic skin response; NM nictitating membrane; ISI, interstimulus interval. *Unrestrained. †Drug paralysis. All other subjects were restrained, undrugged.

before the heart rate $C R$. This may be confounded by the involvement of heart rate changes in skeletal movements such as barpressing. In addition, the actual behavior of the animal during conditioned suppression is unknown.

Rows 3-4 each contain data for the GSR and heart rate in the same animal. Here, the first CR for the two systems appears within eight trials. Rows 5-8 all are from groups in which blood pressure and heart rate were measured in the same animal. Within each subject, the first CR appeared in the same trial block for the two responses (within 10 trials). In addition, the data in row 8 include respiration, for which the first $C R$ appeared in the same block of trials (2-10) as did heart rate and blood pressure. Respiration was also measured in rows 9-12; the two conditional responses (heart rate and respiration) developed in the first 10 (row 11) or 20 (rows 9-10) trials. Thus, the data in rows 3-12 emphasize how the quickly acquired CRs develop quickly and concurrently. The studies of most interest in the present review are summarized in rows 11-21. In these experiments, a fast and a slow CR were measured concurrently.

The data in row 11 show a skeletal response-flexionoccurring in the same number of trials as does heart rate in the lizard. However, as discussed earlier, it is not clear that this was a true flexion response.

Rows 12-21 are for the concurrent measure of NM and heart rate. In 2 out of 10 groups, NM and heart rate CRs appeared in the same trial block (rows 20 and 21 ). In contrast, in most cases ( 7 out of 10), heart rate CRs were acquired first. In one group, heart rate CRs, but not NM CRs, developed (row 19). Thus, the heart rate response developed before the NM CR in 8 out of 10 cases. This was true even though this was not the optimal condition for assessing such differences because the data were reported in large trial blocks (40 trials). The group in row 12 also had a respiration measurement, for which the first CR appeared in the same block as did heart rate, both before the NM CR.

One might argue that the difference in learning rate reflects the use of an ISI that was optimal for heart rate but at which NM conditioning is retarded or impossible. For example, the data in row 19 come from a study (VanDercar \& Schneiderman, 1967) in which the ISI was $6.75 \mathrm{sec}$; the cardiac CR did appear (although retarded compared to the results of other studies, 41-80 trials), but the NM CR did not develop. Because this long ISI was beyond the range of NM conditioning, the difference in conditioning rate cannot be attributed to the type of response system studied. This is a fully justified argument in this case. A similar argument could be made for the data summarized in row 15, for which the ISI was $2.25 \mathrm{sec}$. Moreover, in two studies for which the heart rate and NM CRs were acquired in the same trial block (rows 20 and 21 ), the ISIs were much smaller-0.25 and $0.35 \mathrm{sec}$, which are near optimal for the NM. As discussed previously, large trial blocks (in these cases, blocks of $\mathbf{4 0}$ trials) make it difficult to detect a difference in acquisition rate; recall that the mean for heart rate conditioning is $\mathbf{8 . 4}$ trials, whereas the mean for NM is $\mathbf{5 9 . 2}$ trials (Figure 1).

In any event, further inspection of Table 1 indicates that this argument does not explain other findings. For example, ISIs of $0.35,0.70$, and $0.75 \mathrm{sec}$ were used in the studies whose data are summarized in rows 16,12 , and 14 , respectively. In all three cases, heart rate conditioning developed in the block of trials preceding that in which 
the NM CR developed, despite the use of large trial blocks ( 25 or 40 trials), which would tend to obscure such differences.

Sorely needed are more experiments to compare the acquisition of different responses within the same animal. Moreover, it would be extremely informative to concurrently measure several systems and have as independent variables a variety of the factors known to affect acquisition rate-CS intensity and so forth. This would allow an analysis of whether various CRs are differentially affected by these variables. For example, reliable, fast cardiac conditioning can be obtained in the guinea pig using an extremely weak CS of $0 \mathrm{~dB}$ (Anderson, 1972). Can other CRs be acquired with a CS of this low an intensity? Such experiments would provide a rich database for discovering relationships among various response systems and so provide a more comprehensive understanding of how various conditioned responses are related to the overall adaptive behavior of an organism.

\section{Summary of Results}

The data for the single response systems and the multiple response systems within an animal indicate a bimodal distribution of the number of trials to first $C R$ in the various response systems. There appears to be a group of responses that show fast acquisition during conditioning and a group for which acquisition is slower. The former group consists of GSR, conditioned suppression, blood pressure, respiration, pupil, and heart rate, and the latter group consists of flexion (tail or limb), NM, and eyelid. Furthermore, other variables such as CS intensity, US intensity, ITI, and ISI do not account for this dichotomy.

\section{VALIDITY OF THE SURVEY}

In this section, we will examine the validity of the survey with respect to (1) percent versus magnitude as measures of CR, (2) trial block size, and (3) the problem of relying on acquisition data.

\section{CR Measurement}

Classical conditioning can be assessed either as a magnitude change or in terms of percent CRs. This could potentially complicate the interpretation of the present survey, because we made no attempt to control for this factor. Indeed, it would be extremely difficult to do so, because, for example, while heart rate and conditioned suppression are usually measured in terms of magnitude of response (amount of change of heart rate or suppression), responses such as flexion and NM extension are often measured in percent CRs (percent of responses exceeding some criterion). In classical conditioning studies in which the CRs have been measured in two different ways, the results of the investigations have been similar regardless of the method used. VanDercar and Schneiderman (1967), in their simultaneous measurement of heart rate and NM, measured heart rate as both magnitude of change and percent CRs. Their findings about optimal ISI for heart rate were unaffected by the method of measurement. Similarly, Smith (1968), in an NM study of CS-US interval and US intensity, found that measuring the percent CRs or amplitude of CRs yielded the same results. Thus, it is highly unlikely that differences in how the conditioning is assessed can explain the results of the present survey.

\section{Trial Block Size}

Determining the appearance of the first consistent CR was somewhat hampered by the fact that many studies use blocks of 25 or more trials in their acquisition graphs. Large trial blocks could yield a conservative estimate of the rate of acquisition. Moreover, they could prevent detection of a difference in trials to the first CR for different response systems. An analysis of trial block size reveals that researchers use larger trial blocks for slower CRs than for the faster CRs $(33.9 \pm 38.3$ vs. $5.8 \pm 5.2$ trials, $p \leq .0001$ ) (Figure 5).

It might be argued that the large block size tends to give a false overestimate for the slow CRs, because the midpoint of a larger trial block is larger than the midpoint of a smaller block with the same starting point. Thus, a greater value for the first CR for the slow CRs might simply reflect a larger block size. However, in many cases in which the trial blocks were large, the first CR did not appear in the first block; such cases almost exclusively were for NM, flexion, and eyelid conditioning. Therefore, block size is not responsible for the differences in acquisition rate.

\section{Trial Block Size for Fast and Slow Conditioned Responses}

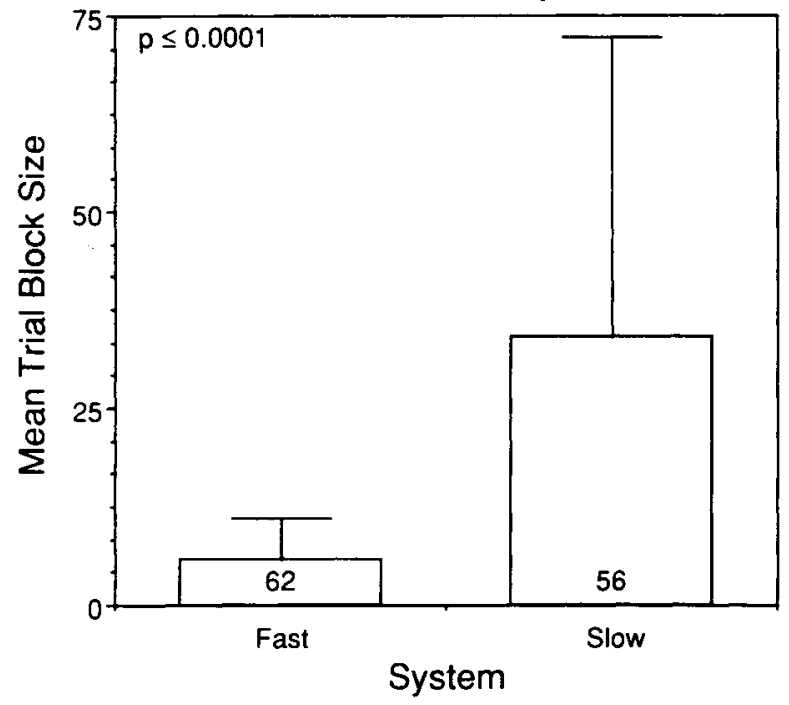

Figure 5. Trial block size used in presentations of learning rate curves for "fast" and "slow" systems. It is clear that the "slower" systems are presented in larger blocks of trials. The error bars represent standard deviations. 
It should be stressed that trial block size is decided by the experimenter. This choice is not arbitrary; it is based on the rate of acquisition of the response. Thus, the responses that condition more slowly are presented in larger trial blocks-smaller blocks would result in a graph in which the first CR was not apparent until well into the graph. Such large blocks summarize the data more efficiently, and they give the graph a "smoother" appearance.

The different ways in which acquisition data for the slow and fast responses are presented are especially apparent in a report of conditioning of heart rate and NM (not concurrently) in the rabbit (Lavond, Lincoln, McCormick, \& Thompson, 1984). In this paper, heart rate is plotted in blocks of 5 trials, whereas the NM data are presented in blocks of 30 trials.

In summary, the different sizes of trial blocks in reports of acquisition functions cannot explain the differences in acquisition rates between the fast and slow response systems.

\section{Reliance on Acquisition Data}

Acquisition data are subject to performance variables such as attention and motivation, so that some workers believe that such data should never be used in the attempt to understand either the behavioral or the neurobiological aspects of conditioning (see, e.g., Rescorla, 1988). In spite of such admonitions, the present article is quite specifically and deliberately based on acquisition data, for two reasons. First, alternative data are not available. ${ }^{3} \mathrm{Sec}-$ ond, detailed consideration of the acquisition data, rather than a priori dismissal of these data, reveals that alleged performance factors cannot account for the bimodal distribution of learning rates between the two types of CRs, as follows.

First, performance variables during acquisition could not enable slowly acquired CRs to appear to be rapidly acquired CRs. This might occur for sensitized responses, but there are adequate controls for nonassociative factors in the survey. For example, rapidly acquired pupillary dilation CRs are due to associative factors rather than to sensitization. Therefore, we conclude that rapidly acquired CRs are not actually slowly acquired CRs whose rate of development has been somehow greatly facilitated by some performance factor. It follows that rapidly acquired CRs are real. Moreover, it follows that either all CRs are rapidly acquired or only some are rapidly acquired.

Second, if all CRs develop rapidly but performance factors retard the rate at which this development is expressed for NM, flexion, and eyelid response systems, these slowly acquired CRs must actually develop as rapidly as do the rapidly acquired CRs, although this development would be confined to the brain and not expressed behaviorally until much later. But slowly acquired CRs characteristically become precisely timed to appear immediately before presentation of the US. Even when they appear early in a CS-US interval, the maximum response often increases its latency over many trials to "peak" immediately before US onset. The idea that precise timing of NM, eyelid, or flexion CRs develops neurally during the first 5-10 trials of training is extremely difficult to reconcile with the finding that this timing develops behaviorally over a much larger number of trials.

Third, to argue that the eyelid, NM, and flexion CRs are rapidly acquired within the brain but not expressed because of some performance factors, within-subject findings must be accounted for. Within-subject simultaneous measurement of heart rate and NM CRs shows that the former develop more rapidly than the latter (see also Powell \& Levine-Bryce, 1988). One would have to argue that certain performance factors act specifically to retard the appearance of the NM CR but have no effect on the heart rate $\mathrm{CR}$. The existence of such factors remains to be demonstrated.

Martin and Levey (1969) postulated that during classical conditioning, a "crude"' model of the response forms at the cortical level, and that various factors (UCS intensity, inhibition build-up, state of the animal) determine whether the overt behavioral response appears. This was based partly on observations made in human eyeblink conditioning. When a subject produces the first CR relatively late in training compared to the group data, the efficiency of the CR (which is partially reflected as CR amplitude) is normal compared to the group data at that point, suggesting that there was development of some covert response previous to the overt response. However, in the rabbit NM preparation, actual neural recordings from the cerebellum (the locus of the putative "engram" for this response) reveal that conditioned neural responses do not appear much earlier, if they appear at all, than the behavioral responses (McCormick, Clark, Lavond, \& Thompson, 1982). In this preparation, neural response changes do appear in the hippocampus within 10 trials (Berger \& Thompson, 1978), but changes are also observed in the hippocampus during conditioned suppression training (Edeline, Dutrieux, \& Neuenschwander-El-Massioui, 1988); thus, the hippocampal responses do not seem to be specific to the NM response.

The present survey may at least prove to be heuristic even for workers who would categorically ignore any findings based on acquisition data, without closer examination of the data themselves. The alternative is to discard an extensive literature because some alleged and possibly nonexistent factors might affect the NM, eyelid, and flexion CRs but not other CRs. This is unreasonable. In summary, an a priori and categorical dismissal of the acquisition data in the present survey is unwarranted. The differences in acquisition rates between the fast and slow CRs are not explicable by performance factors.

\section{INTERPRETATION OF FINDINGS}

The major finding of this literature survey was that the responses in one group (GSR, conditioned suppression, blood pressure, respiration, pupil, and heart rate) develop a conditional response before those in another group (flexion, NM, and eyeblink). Furthermore, this bimodal distribution is best explained as being a result of the response 
system itself, rather than being due to other variables that affect the rate of conditioning. What is the significance of this finding? To put it another way, what is the nature of this dichotomy? Below, we will briefly consider diffuse versus precise, autonomic versus skeletal, preparatory versus consummatory, and specific versus nonspecific CRs as representing four types of distinction.

\section{Diffuse-Precise}

Schlosberg (1937) distinguished between rapidly acquired diffuse and more slowly acquired precise CRs. He considered the diffuse responses to be "emotional" or "anticipatory," and the precise ones, "adaptive." How well do the results of the present survey fit this framework?

Without too much difficulty, the NM, eyeblink, and flexion responses can be viewed as precise. Each of these is specific to the US delivered. But, how adaptive are they? An eyeblink or NM response might ameliorate the effects of an air puff. But how does such a response ameliorate an eye shock, or, in the case of footshock, how does a leg flexion decrease the noxious quality of this stimulus? (But see Behavioral Inquiry, below.) Also, the rapidly acquired CRs could serve some adaptive function, or at least index a central state of preparedness that might reduce the overall noxious effects of the US. A precise explication of the meaning of adaptive is probably needed before the various CRs can be assessed in the terms advanced by Schlosberg.

As for referring to the other responses as "diffuse" and "preparatory," these terms are not well defined. If diffuse is taken to refer to general responses that are not adaptive with regard to a certain US, then perhaps heart rate, GSR, etc., can be considered diffuse; they occur in response to a shock regardless of where it is applied. In any event, Schlosberg's use of the precise-diffuse distinction, while perhaps valid, suffers from unclear definition.

\section{Autonomic-Skeletal}

Mowrer (1947) proposed a distinction between autonomic and somatic CRs. The findings of the survey appear to generally fit this distinction. GSR, blood pressure, pupil, and heart rate CRs are all autonomic, and NM, eyelid, and leg flexion CRs are somatic. Respiration, however, can be controlled voluntarily. If the conditioned component is autonomic, this could be classified with the autonomic responses. But this still leaves conditioned suppression. Little is known about the physiological and behavioral processes during suppression, so it is difficult to categorize this CR. Perhaps, because it involves cessation of motor activity (bar pressing), suppression can be considered somatic. If so, it must be an anomaly, for Mowrer maintained that such skeletal responses are acquired more slowly than autonomic responses are.

In addition, Konorski (1967) cited motor arousal as an example of an early CR. This is a somatic response, yet it conditions rapidly. The autonomic-skeletal distinction thus seems to be inadequate to explain all of the data.

\section{Preparatory-Consummatory}

The preparatory-consummatory distinction was developed by Konorski (1967). More specifically, with regard to defensive conditioning, the separation was made between fear CRs and shock CRs. The fear CRs are characterized by sympathetic outflow, and the shock CRs, by responses such as flexion. According to Konorski, the preparatory CRs develop first.

The observed autonomic changes in the various studies summarized here could be indicators of fear, as could conditioned suppression (Estes \& Skinner, 1941). Flexion, $\mathrm{NM}$, and eyelid CRs are classified as consummatory; they are directed toward the US itself.

The results of the survey fit the preparatory-consummatory distinction quite well. The problem is that the use of such labels implies acceptance of Konorski's theoretical framework or at least his functional categories. However, the functional interpretation requires independent verification.

\section{Nonspecific-Specific}

Konorski (1967) noted that CRs can be directed toward removal or relief from a noxious stimulus or be of a more general nature. Following this, Weinberger has emphasized this type of distinction, adhering to a functionally neutral classification, based solely on whether the CRs are specific or not to the US (Weinberger, 1982; Weinberger, Diamond, \& McKenna, 1984). Specific CRs are those that occur in the response system of the unconditioned response. Nonspecific CRs occur regardless of the type or locus of the US.

An example of a specific CR is that of the NM, which is not only specific to the eye but also localized to the left or right eye, depending. on which eye has received the US and produced a UR. The pupillary dilation CR is also an ocular CR, but its development does not require stimulation of the region of the eye, as for the NM response; moreover, it can develop with various USs, such as electrocutaneous stimulation of various locations on the body surface, and others. The nonspecific CRs occur in any Pavlovian defensive classical conditioning situation (Weinberger, 1982; Weinberger, Diamond, \& McKenna, 1984). Table 1 supports this idea: when two or more nonspecific CRs (heart rate, blood pressure, respiration, GSR) are recorded simultaneously, they both or all develop quickly.

With regard to the present review of the literature, the rapidly conditioning responses do seem to be nonspecific to the US, and the more slowly developing responses appear to be specific to the unconditioned stimulus. For example, a leg flexion occurs in response to a footshock, an eyeblink to a shock in the face area, and a cardiac CR develops to both.

\section{Summary}

Four theoretical dichotomies have been considered within which the results of the present survey could be placed: diffuse versus precise, autonomic versus skeletal, preparatory versus consummatory, and nonspecific 
versus specific CRs. All have merit and are not necessarily incompatible. The nonspecific-specific distinction, with regard to the US, appears to be relatively neutral from a functional standpoint. Interpretations based on functional distinctions require experimental verification. Regardless of preference for one or another version of two-factor interpretations of Pavlovian defensive conditioning, this survey supports the view that the rate of acquisition is a function of the type of response system.

\section{IMPLICATIONS FOR BEHAVIORAL AND NEUROBIOLOGICAL STUDIES}

The apparent simplicity of recording a response seems to play a role in determining which response is measured in studies of classical conditioning. The assumption seems to be that as long as a CR is obtained, the response system is not critical. In light of the results of this review, such an assumption may be unwise. Some of the implications of the dichotomy between quickly acquired and more slowly acquired CRs are discussed below.

\section{Behavioral Inquiry}

The results of the survey can lead to various functional interpretations, all of which require empirical study. We favor a type of interpretation similar to that advanced by theorists previous to the present finding of a bimodal distribution of acquisition rates. The major implication is that Pavlovian aversive conditioning consists of two stages which are concerned with different aspects of learning.

The first stage consists of learning an association between the CS and the US. This is indexed by the development of nonspecific CRs. In a real sense, for example, the heart or the pupil is not being conditioned; rather, the organism is being conditioned. The rapidly developing CRs index this process. At this stage, the organism has not learned how to deal externally with the US. However, the first stage of conditioning may provide a means for lessening the noxious impact of the US within the brain. Thus, the CS appears to acquire the ability to produce analgesia (Bolles \& Fanselow, 1980; Chance, White, Krynock, \& Rosecrans, 1979; Fanselow \& Bolles, 1979; see also Fanselow \& Helmstetter, 1988).

The second stage consists of learning an association between a CS and a CR. That is, the animal learns to make a specific CR that is directed at the US, often with precise timing. This is indexed by a slowly acquired CR. Although complete avoidance of the US is not possible in a well-constructed Pavlovian situation, amelioration of the noxious impact may be possible. During animal-initiated limb flexion, for example, cutaneous ascending volleys can be reduced at the synapses in the dorsal column medial leminiscus system, presumably by the established descending cortical control of afferent paths; this does not occur if the limb is flexed passively by the experimenter (Coulter, 1974; Ghez \& Lenzi, 1971; Ghez \& Pisa, 1972). Thus, flexion CRs could reduce the intensity of the noxious shock to the paw (US) centrally if not peripherally.
Both stages are essential for behavioral adaptation. Thus, the fact that some CRs are acquired slowly does not in any sense render them less important or less interesting than CRs that are acquired rapidly. The only primacy that might accrue to the latter is that the processes involved in the acquisition of rapidly acquired CRs might be essential for or involved in some way in the acquisition of the more slowly acquired, specific CRs. For example, rapid CS-US learning may represent a central motivational state, such as conditioned fear ${ }^{4}$ (Rescorla \& Solomon, 1967), which is necessary for learning the appropriate specific CR for each situation. Alternatively, instead of a serial relationship, the two types of CRs might result from parallel processes, although we think this unlikely. The relationship between the processes underlying the two classes of CRs is not yet understood.

In addition to providing strong support for two stages of conditioning, the present survey has practical implications. For example, the response system that is chosen in behavioral studies may very well influence the results, as Yehle (1968) emphasized in his work on three-tone discrimination in rabbits. Yehle recorded heart rate, respiration, and NM responses concurrently. The behavior of these three response systems differed greatly. Yehle pointed out that if only heart rate had been measured, he would have concluded that some sort of adaptation or reactive inhibition had occurred; the response appeared early and demonstrated discrimination, but the response level decreased over trials. If only the NM responses had been recorded, the conclusion would have been that normal acquisition had taken place. And if only the respiration measure had been recorded, the conclusion would have been that three-tone discriminations were beyond the rabbit's ability.

In summary, a complete account of aversive Pavlovian conditioning, a paradigm that has been used extensively to understand learning, requires a theory that can transcend both any particular CR and a single class of CRs. As set forth here, the classes are distinguished on the basis of a bimodal rate of development of CRs.

\section{Implications for the Neurobiology of Learning}

A major implication for neurobiological studies of aversive conditioning is that the mechanisms of the learning that takes place in this situation are more extensive than the mechanisms that underlie a single selected CR. This follows from the fact that a single behavioral $C R$ is not even an adequate behavioral indication of what is learned. Thus, it would be erroneous to focus on the neural mechanisms underlying a single rapidly or slowly acquired CR in the quest to obtain an adequate account of conditioning. This type of approach can yield only a fragmentary understanding of the neural bases of aversive conditioning.

This is not to say that the neuronal laws of conditioning can be gleaned only from an exhaustive analysis of all possible behavioral CRs. Neuronal laws discovered under one set of measurement circumstances can be tested for their general applicability to other measurement or 
training circumstances, or both. The present findings suggest that the level at which fundamental differences in neural laws of conditioning will be found pertains to the neural processes that are reflected in the two types of behavioral CRs that have been revealed by the present analysis of the rates of conditioning.

A practical neurobiological implication concerns potential conclusions about critical brain structures in conditioning, which may be affected by the type of CR measured. For example, Lavond et al. (1984) found that, within the same subjects, lesions of the medial dentate/lateral interpositus nuclei abolished the NM CR but that they had no effect on the heart rate CR. This assessment of the effects of a treatment on the two types (fast and slow) of CRs can help elucidate both the nature of the learning deficit and the relationship between the neural mechanisms of learning that are expressed in the two types of CRs. (See, e.g., Kao \& Powell, 1986; Powell \& Buchanan, 1980; Powell, Mankowski, \& Buchanan, 1978.)

Finally, the results of this survey emphasize the caution that one must exercise in referring to a classical conditioning preparation as a "model" preparation. It may very well only be a model for that class of response which has been selected for measurement. Workers in allied fields who are not conversant with fundamental aspects of learning and conditioning may wrongly conclude that certain findings provide insights into general neural laws of association when in actuality they apply only to a single response system or type of response system.

\section{CONCLUSIONS}

The simplicity of the procedures involved in Pavlovian aversive conditioning tends to obscure the complexity of the learning processes involved. To say that an animal has learned a conditioned leg flexion response or a conditioned heart rate response is not a complete description of what has occurred. What researchers use to index learning is only one of many responses conditioned during aversive Pavlovian procedures; the parameters selected by the experimenter are usually the ones that are optimal for the behavioral response system under study. The differences in acquisition rates of the specific and nonspecific CRs must be kept in mind in the design of experiments. In addition, the division of classically conditioned responses into the quickly learned nonspecific and the slower specific systems-and the possible dependence of the former on the latter-is further evidence that "simple" classical conditioning is a misnomer. Mackintosh (1985) has stressed that the neurobiology of conditioning is far more interesting than most neuroscientists have acknowledged. The data reviewed and discussed here support such a notion. The results also serve to warn those who are interested in behavioral and neurobiological aspects of Pavlovian defensive conditioning that the choice of a response system should not be arbitrary, but should be made with due consideration to the type of question being asked, and that generalizations of the results need to be constrained by prior findings in the field of conditioning. Thus, analysis of a slowly acquired $\mathrm{CR}$, such as the NM CR, should take into account findings from studies of rapidly acquired CRs, such as heart rate, and vice versa.

Finally, it seems patently obvious that generalizations about either the behavioral or the neurobiological bases of Pavlovian conditioning should not be made on the basis of investigating either a rapidly or a slowly acquired $\mathrm{CR}$. It follows that the deliberate decision to limit the neurobiological analysis of learning to the study of slowly acquired CRs (Schreurs, 1989) is wrong-minded, excessively narrow, misleading, and unfounded either in logic or in fact.

\section{REFERENCES}

ANDERSON, D. E. (1972). Heart-rate conditioning to a pure tone in the guinea pig. Psychonomic Science, 26, 47-48.

AnNaU, Z., \& KAMIN, L. J. (1961). The conditioned emotional response as a function of intensity of the US. Journal of Comparative \& Physiological Psychology, 54, 428-432.

Ashe, J. H., Cassady, J. M., \&e Weinberger, N. M. (1976). The relationship of the cochlear microphonic potential to the acquisition of a classically conditioned pupillary dilation response. Behavioral Biology, 16, 45-62.

Ashe, J. H., COOPER, C. L. (1978). Multifiber efferent activity in postganglionic sympathetic nerves related to the latency of spontaneous and evoked pupillary dilation response. Experimental Neurology, 59, 413-434.

Ashe, J. H.,Cooper, C. L., We Weingerger, N. M. (1978a). Mescencephalic multiple-unit activity during acquisition of conditioned pupillary dilation. Brain Research Bulletin, 3, 143-154.

Ashe, J. H.,CoOper, C. L., Weinberger, N. M. (1978b). Role of the parasympathetic pupillomotor system in classically conditioned pupillary dilation of the cat. Behavioral Biology, 23, 1-13.

BARNes, G. W. (1956). Conditioned stimulus intensity and temporal factors in spaced-trial classical conditioning. Journal of Experimental Psychology, 51, 192-198.

Berger, T. W., Thompson, R. F. (1978). Neuronal plasticity in the limbic system during classical conditioning of the rabbit nictitating membrane response: I. The hippocampus. Brain Research, 145, 323-346.

BLACK, A. H. (1965). Cardiac conditioning in curarized dogs: The relationship between heart rate and skeletal behavior. In W. F. Prokasy (Ed.), Classical conditioning: A symposium (pp. 20-47). New York: Appleton-Century-Crofts.

Bloch-Rojas, S., Toro, A., \& Pinto-Hamuy, T. (1964). Cardiac versus somatomotor conditioned responses in neodecorticate rats. Journal of Comparative \& Physiological Psychology, 58, 233-236.

Bolles, R. C., \& FAnselow, M. S. (1980). A perceptual-defensiverecuperative model of fear and pain. Behavioral \& Brain Sciences, 3, 291-301.

Burdick, C. K., \& James, J. P. (1973). Effects of a backward conditioning procedure following acquisition on extinction of conditioned suppression. Animal Learning \& Behavior, 1, 137-139.

Cegavske, C. F., Harrison, T. A., Torigoe, Y. (1987). Identification of the substrates of the unconditioned response in the classically conditioned rabbit, nictitating membrane preparation. In I. Gormezano, W. F. Prokasy, \& R. F. Thompson (Eds.), Classical conditioning (pp. 65-91). Hillsdale, NJ: Erlbaum.

Cegavske, C. F., Thompson, R. F., Patterson, M. M., \& GorMEZANO, 1. (1976). Mechanisms of efferent neuronal control of the reflex nictitating membrane response in the rabbit. Journal of Comparative \& Physiological Psychology, 90, 411-423.

Снасто, C., Lubow, R. E. (1967). Classical conditioning and latent inhibition in the white rat. Psychonomic Science, 9, 135-136. 
Champion, R. A. (1962). Stimulus-response contiguity in classical aversive conditioning. Joumal of Experimental Psychology, 64, 35-39.

Chance, W. T., White, A. C., Krynock, G. M., Rosecrans, J. A. (1979). Auto analgesia: Acquisition, blockade and relationship to opiate binding. European Joumal of Pharmacology, 58, 461-468.

ClYNeS, M. (1960). Computer analysis of reflex control and organization: Respiratory sinus arrhythmia. Science, 131, 300-302.

Cohen, D. H., Durkovic, R. G. (1966). Cardiac and respiratory conditioning, differentiation, and extinction in the pigeon. Journal of the Experimental Analysis of Behavior, 9.681-688.

Cohen, D. H., \& Pitrs, L. H. (1968). Vagal and sympathetic components of conditioned cardioacceleration in the pigeon. Brain Research, 9, 15-31.

Cohen, D. H., RANDall, D. C. (1984). Classical conditioning of cardiovascular responses. Annual Review of Physiology, 46, 187-197.

Coulter, J. D. (1974). Sensory transmission through lemniscal pathway during voluntary movement in the cat. Joumal of Neurophysiology, 37, 831-845.

Davidson, R. E., Richardson, A. M. (1970). Classical conditioning of skeletal and autonomic responses in the lizard (Crotaphytus collaris). Physiology \& Behavior, 5, 589-594.

DAvis, R. E., Holmes, P. A. (1971). ECS-produced retrograde amnesia of conditioned inhibition of respiration in cataleptic goldfish. Physiology \& Behavior, 7, 11-14.

DEToledo, L., BlaCK, A. H. (1966). Heart rate: Changes during conditioned suppression in rats. Science, 152, 1404-1406.

Diamond, D. M. (1985). Physiological plasticity of single neurons in auditory conex of the cat during learning. Unpublished doctoral dissertation, University of California, Irvine.

Dinmond, D. M., We Winberger, N. M. (1984). Physiological plasticity of single neurons in auditory cortex of the cat during acquisition of the pupillary conditioned response: II. Secondary field (AII). Behavioral Neuroscience, 98, 189-210.

Dickinson, A., Dearing, M. F. (1979). Appetitive-aversive interactions and inhibitory processes. In A. Dickinson \& R. A. Boakes (Eds.), Mechanisms of learming and motivation: A memorial volume to Jerzy Konorski (pp. 203-232). Hillsdale, NJ: Erlbaum.

Durkovic, R. G., COHEN, D. H. (1969). Effect of caudal midbrain lesions on conditioning of heart and respiratory-rate responses in the pigeon. Journal of Comparative \& Physiological Psychology, 69, 329-338.

Dykman, R. A., GANTT, W. H. (1959). The parasympathetic component of unlearned and acquired cardiac responses. Journal of Comparative \& Physiological Psychology, 52, 163-167.

ECKERT, R., RANDALL, R. (1978). Animal physiology. San Francisco: W. H. Freeman.

Edelne, J.-M., Dutrieux, G., \& Neuenschwander-El-Massiou, N. (1988). Multiunit changes in hippocampus and modial geniculate body in free-behaving rats during acquisition and retention of a conditioned response to a tone. Behavioral and Neural Biology, 50, 61-79.

Edeline, J.-M., Weinberger, N. M. (1991a). Subcortical adaptive filtering in the auditory system: Associative receptive field plasticity in the dorsal medial geniculate body. Behavioral Neuroscience, 105, 154-175.

Edeline, J.-M., Weingerger, N. M. (1991b). Thalamic short-term plasticity in the auditory system: Associative retuning of receptive fields in the ventral medial geniculate body. Behavioral Neuroscience, 105, 618-639.

Edeline, J.-M., \& Weinberger, N. M. (1992). Retuning of auditory neurons at the thalamic interface between cortex and amygdala: Receptive field plasticity in the medial division of the medial geniculate body. Behavioral Neuroscience, 106, 81-105.

Estes, W. K., SKINNER, B. F. (1941). Some quantitative properties of anxiety. Journal of Experimental Psychology, 29, 390-400.

FANSELOW, M. S., Bolles, R. C. (1979). Triggering of the endorphin analgesic reaction by a cue previously associated with shock: Reversal by naloxone. Bulletin of the Psychonomic Sociery, 14, 88-90.

Fanselow, M. S., Helmstetter, F. J. (1988). Conditional analgesia, defensive freezing, and benzodiazepines. Behavioral Neuroscience, 102, 233-243.

Fenr, F. S., a Stern, J. A. (1965). Heart rate conditioning in the rat. Journal of Psychosomatic Research, 8, 441-453.
FitzGerald, R. D. (1966). Some effects of partial reinforcement with shock on classically conditioned heart-rate in dogs. American Journal of Psychology, 79, 242-249.

Fitzgerald, R. D., Martin, G. K., O'Brien, J. H. (1973). Influ ence of vagal activity on classically conditioned heart rate in rats. Jowrnal of Comparative \& Physiological Psychology, 83, 485-491.

Fitzgernid, R. D., Teyler, T. J. (1970). Trace and delayed heartrate conditioning in rats as a function of US intensity. Joumal of Comparative \& Physiological Psychology, 70, 242-253.

Fttzgerald, R. D.,VArdarus, R. M., Teyler, T. J. (1966). Effects of partial reinforcement followed by continuous reinforcement on classically conditioned heart rate in the dog. Joumal of Comparative \& Physiological Psychology, 62, 483-486.

FowLES, D. C. (1974). Mechanisms of electrodermal activity. In R. F Thompson \& M. M. Patterson (Eds.), Bioelectric recording tech niques: Pt. C. Receptor and effector processes (pp. 231-271). New York: Academic Press.

Frey, P. W., \& Butler, C. S. (1973). Rabbit eyelid conditioning as a function of unconditioned stimulus duration. Joumal of Comparative \& Physiological Psychology, 85, 289-294.

Frey, P. W., BUtler, C. S. (1977). Extinction after aversive conditioning: An associative or nonassociative process? Leaming \& Motivation, 8, 1-17.

FrEY, P. W., \& Ross, L. E. (1968). Classical conditioning of the rabbit eyelid response as a function of interstimulus interval. Jourmal of Comparative \& Physiological Psychology, 65, 246-250.

GANTT, W. H. (1960). Cardiovascular component of the conditional reflex to pain, food, and other stimuli. Physiological Reviews, 40. 266-291.

Gerall, A. A., ObRest, P. A. (1962). Classical conditioning of the pupillary dilation response of normal and curarized cats. Joumal of Comparative \& Physiological Psychology, 55, 486-491.

Ghez, C.. \& LenzI, G. L. (1971). Modulation of sensory transmission in cat lemniscal system during voluntary movement. European Journal of Physiology, 323, 272-278.

GHEZ, C.. PISA, M. (1972). Inhibition of afferent transmission in cunate nucleus during voluntary movement in the cal. Brain Research, 40, 145-151.

Ginn, S. R., Valentine, J. D.. * Powell, D. A. (1983). Concomitant Pavlovian conditioning of heart rate and leg flexion responses in the rat. Pavlovian Joumal of Biological Science, 18, 154-160.

Gold, M. R., CoHEN, D. H. (1981). Heart rate conditioning in the pigeon immobilized with alpha-bungarotoxin. Brain Research, 216, 163-172.

GoLw, S., Goun, A. K. (1966). Incubation and inhibition. Journal of Experimental Psychology, 71, 208-211.

Gormezano, I., Coleman, S. R. (1975). Effects of partial reinforcement on conditioning, conditional probabilities, asymptotic performance, and extinction of the rabbit's nictitating membrane response. Pavlovian Joumal of Biological Science, 10, 13-22.

Gormezano, I., Kehoe, E. J., \& Marshall, B. S. (1983). Twenty years of classical conditioning research with the rabbit. Progress in Psychobiology \& Physiological Psychology, 10, 197-275.

Gormezano, I., Prokasy, W. F., a Thompson, R. F. (Eds.) (1987). Classical conditioning (3rd ed.). Hillsdale, NJ: Erlbaum.

Gormezano, I., Schineiderman, N., Deaux, E., a Fuentes, 1. (1962). Nictitating membrane: Classical conditioning and extinction in the albino rabbit. Science, 138, 33-34.

Graves, C. A., Solomon, P. R. (1985). Age-related disruption of trace but not delay classical conditioning of the rabbit's nictitating membrane response. Behavioral Neuroscience, 99, 88-96.

GraY, T. (1979). Sudden, rapid acquisition of conditioned suppression (CER). Animal Learning \& Behavior, 7, 351-354.

GreverT, P., MoORE, J. W. (1970). The effects of unpaired US presentations on conditioning of the rabbit's nictitating membrane response: Consolidation or contingency. Psychonomic Science, 20. 177-179.

Grings, W. W. (1974). Recording of electrodermal phenomena. In R. F Thompson \& M. M. Patterson (Eds.), Bioelectric recording rechniques. Pt. C. Receptor and effector processes (pp. 273-296). New York: Academic Press.

Gruber, S. H., Schneiderman, N. (1975). Classical conditioning 
of the nictitating membrane response of the lemon shark (Negaprion brevirostris). Behavior Research Methods \& Instrumentation, 7, 430-434.

Gustafson, J. W., Lindsky, T. I., \& Schwartzbaum, J. S. (1975). Effects of hippocampal stimulation on acquisition, extinction, and generalization of conditioned suppression in the rat. Joumal of Comparative \& Physiological Psychology, 89, 1136-1148.

Gutmann, W., Brozek, G., \& Bures, J. (1972). Cross modal transfer and neurophysiological mechanisms of conditioned eye blink in the rabbit. Activitas Nervosa Superior, 14, 241-245.

HARris, A. H., BRADY, J. V. (1974). Animal learning-visceral and automatic conditioning. Annual Review of Psychology, 25, 107-133.

Hilgard, E. R., Marquis, D. G. (1935). Acquisition, extinction and retention of conditioned lid responses to light in dogs. Journal of Comparative Psychology, 19, 29-58.

Hofmuan, J. W., Fitzgerald, R. D. (1978). Classically conditioned heart rate and blood pressure in rats based on either electric shock or ammonia fumes reinforcement. Physiology \& Behavior, 21, 735-741.

Holdstock, T. L., Schwartzbaum, J. S. (1965). Classical conditioning of heart rate and galvanic skin response in the rat. Psychophysiology, 2, 25-38.

HoRTON, G. P. (1933). A quantitative study of hearing in the guinea pig (Cavia cobaya). Joumal of Comparative Psychology, 15, 59-73.

HUTtenlocher, J., \& WestcotT, M. R. (1957). Some empirical relationships between respiration and heart-rate. American Psychologist, $12,414$.

IWATA, J., LeDoux, J. E. (1988). Dissociation of associative and nonassociative concomitants of classical fear conditioning in the freely behaving rat. Behavioral Neuroscience, 102, 66-76.

James, J. P., Shangi, L., Pangman, C., Mostoway, W. (1973). The role of number and spacing of CS-US pairings in conditioned suppression. Animal Learning \& Behavior, 1, 140-144.

KAMIN, L. J. (1961). Apparent adaptation effects in the acquisition of a conditioned emotional response. Canadian Joumal of Psychology, 15, 176-188.

KAMIN, L. J. (1963). Backward conditioning and the conditioned emotional response. Journal of Comparative \& Physiological Psychology, 56, 517-519.

KAo, K., Powell, D. A. (1986). Lesions of substantia nigra retard Pavlovian somatomotor learning but do not affect autonomic conditioning. Neuroscience Letters, 64, 1-6.

Kappauf, W. E., SChlosberg, H. (1937). Conditioned responses in the white rat: III. Conditioning as a function of the length of the period of delay. Journal of Genetic Psychology, 50, 27-45.

KeHoe, E. J., \&ormezano, I. (1974). Effects of trial per session on conditioning of the rabbit's nictitating membrane response. Bulletin of the Psychonomic Society, 2, 434-436.

Kimmel, H. D., Kimmel, E. B., Silver, A. I. (1969). The effect of UCS intensity in classical and avoidance GSR conditioning. Conditional Reflex, 4, 32-51.

KoNORSKI, J. (1967). Integrative activity of the brain: An interdisciplinary approach. Chicago: University of Chicago Press.

Lavond, D. G., Lincoln, J. S., McCormck, D. A., Thompson, R. F. (1984). Effects of bilateral lesions of the dentate and interpositus cerebellar nuclei on conditioning of heart-rate and nictitating membrane/eyelid responses in the rabbit. Brain Research, 305, 323-330.

Leonard, D. W., Fishbein, L. C., MonteaU, J. E. (1972). The effects of interpolated US alone (USa) presentations on classical nictitating membrane conditioning in rabbit (Onyctolagus curiculus). Conditional Reflex, 7, 107-114.

LeONARD, D. W., Theios, J. (1967). Classical eyelid conditioning in rabbits under prolonged single alternation conditions of reinforcement. Journal of Comparative \& Physiological Psychology, 64, 273-276.

Levinthal, C. F., Tartell, R. H., Margolin, C. M., \& FishMAN, H. (1985). The CS-US interval (ISI) function in rabbit nictitating membrane response conditioning with very long intertrial intervals. Animal Learning \& Behavior, 13, 228-232.

Lockhart, R. A., Grings, W. W. (1963). Comments on "An analysis of GSR conditioning." Psychological Review, 70, 562-564.
Logan, M. S., Schnur, P. (1976). The effects of nonreinforced and randomly reinforced stimulus preexposure on conditioned suppression in rats. Bulletin of the Psychonomic Society, 8, 336-338.

Lowenstein, O., \& Loewenfeld, I. E. (1969). The pupil. In H. Davson (Ed.), The eye: Vol. 3. Muscular mechanisms (pp. 255-340). New York: Academic Press.

MACKINTOSH, N. J. (1974). The psychology of animal leaming. London: Academic Press.

MackIntosh, N. J. (1985). Varieties of conditioning. In N. M. Weinberger, J. L. McGaugh, \& G. Lynch (Eds.), Memory systems of the brain: Animal and human cognitive processes (pp. 335-350). New York: Guilford.

Martin, G. K., \& FitzGerald, R. D. (1980). Heart rate and somatomotor activity in rats during signalled escape and yoked classical conditioning. Physiology \& Behavior, 25, 519-526.

Martin, I., LeVey, A. B. (1969). The genesis of the classical conditioned response (International Series of Monographs in Experimental Psychology, Vol. 8). London: Pergamon.

McCormick, D. A., Clark, G. A., Lavond, D. G., Thompson, R. F. (1982). Initial localization of the memory trace for a basic form of learning. Proceedings of the National Academy of Science, 79, 2731-2735.

McCormick, D. A., Lavond, D. G., Thompson, R. F. (1982). Concomitant classical conditioning of the rabbit nictitating membrane and eyelid responses: Correlations and implications. Physiology \& Behavior, 28, 769-775.

MCDONALD, D. G., \&ohnson, L. C. (1965). A re-analysis of GSR conditioning. Psychophysiology, 1, 291-295.

Meredith, A. L., Schneiderman, N. (1967). Heart rate and nictitating membrane classical discrimination conditioning in rabbits under delay versus trace procedures. Psychonomic Science, 9, 139-140.

Miller, R. R., Greco, C., Vigorito, M. (1981). Classically conditioned tail flexion in rats: CR-contingent modification of US intensity as a test of the preparatory response hypothesis. Animal Learning \& Behavior, 9, 80-88.

Mis, F. W., Moore, J. W. (1973). Effect of preacquisition UCS exposure on classical conditioning of the rabbit's nictitating membrane response. Learning \& Motivation, 4, 108-114.

MitcheLL, D. S. (1973). Trial distribution effects of postasymptotic performance and retention of the rabbit's (Oryctolagus cuniculus) classically conditioned nictitating membrane response. Journal of Comparative \& Physiological Psychology, 83, 346-350.

MrtchelL, D. S. (1974). Conditional responding and intertrial-interval variability in classical conditioning in the rabbit (Oryctolagus cuniculus). Journal of Comparative \& Physiological Psychology, 87, 73-79.

Morrow, M. C., Seiffert, P. D., \& Kramer, L. L. W. (1970). GSR conditioning and pseudoconditioning with prolonged practice. Psychological Reports, 27, 39-44.

Mowrer, O. H. (1947). On the dual nature of learning-A reinterpretation of "conditioning" and "problem-solving." Harvard Educational Review, 17, 102-148.

O'Brien, J. H., Packham, S. C. (1973). Conditioned leg movement in the cat with massed trials, trace conditioning, and weak US intensity. Conditional Reflex, 8, 116-124.

Obrist, P. A., Sutterer, J. R., \&oward, J. L. (1972). Preparatory cardiac changes: A psychobiological approach. In A. H. Black \& W. F. Prokasy (Eds.), Classical conditioning II: Current research and theory (pp. 312-340). New York: Appleton-Century-Crofts.

Oleson, T. D., Ashe, J. H., Weinberger, N. M. (1975). Modification of auditory and somatosensory system activity during pupillary conditioning in the paralyzed cat. Journal of Neurophysiology, 38, 1114-1139.

Oleson, T. D., Westenberg, I. S., * Weinberger, N. M. (1972). Characteristics of the pupillary dilation response during Pavlovian conditioning in paralyzed cats. Behavioral Biology, 7, 829-840.

PARRISH, J. (1967). Classical discrimination conditioning of heart rate and bar-press suppression in the rat. Psychonomic Science, 9, 267-268.

Pattrerson, M. M. (1970). Classical conditioning of the rabbit's (Oryctolagus cuniculus) nictitating membrane response with fluctuating ISI and intracranial CS. Journal of Comparative \& Physiological Psychology, 72, 193-202. 
Pavlov, I. P. (1927). Conditioned reflexes. New York: Dover.

Plotxin, H. C., OAKLeY, D. A. (1975). Backward conditioning in the rabbit (Oryctolagus cuniculus). Joumal of Comparative \& Physiological Psychology, 88, 586-590.

Plumer, S. I., Siegel, J., \& Cicala, G. A. (1973). Effects of caudate stimulation on classical leg flexion conditioning. Physiological Psychology, 1, 292-296.

Powell, D. A., Buchanan, S. (1980). Autonomic-somatic relationships in the rabbit (Oryctolagus cuniculus): Effects of hippocampal lesions. Physiological Psychology, 8, 455-462.

Powell, D. A., \& Levine-Bryce, D. (1988). A comparison of two model systems of associative learning: Heart rate and eyeblink conditioning in the rabbit. Psychophysiology, 25, 672-682.

Powell, D. A., Mankowski, D., \& Buchanan, S. (1978). Concomitant heart rate and comeoretinal potential conditioning in the rabbit (Oryctolagus cuniculus): Effects of caudate lesions. Physiology \& Behavior, 20, 143-150.

Proxasy, W. F., Ebel, H. C. (1964). GSR conditioning and sensitization as a function of intertrial interval. Journal of Experimental Psychology, 67, 113-119.

Prokasy, W. F., E Ebel, H. C. (1967). Three components of the classically conditioned GSR in human subjects. Joumal of Experimental Psychology, 73, 247-256.

RANDich, A., MAIXNER, W. (1981). Acquisition of conditioned suppression and responsivity to thermal stimulation in spontaneously hypertensive, renal hypertensive and normotensive rats. Physiology \& Behavior, 27, 585-590.

Rescorla, R. A. (1988). Behavioral studies of Pavlovian conditioning. Annual Review of Neuroscience, 11, 329-352.

Rescorla, R. A., Solomon, R. L. (1967). Two-process learning theory: Relationships between Pavlovian conditioning and instrumental learning. Psychological Review, 74, 151-182.

RIESS, D., \& FARRAR, C. H. (1973). UCS duration and conditioned suppression: Acquisition and extinction between-groups and terminal performance within-subjects. Learning \& Motivation, 4, 366-373.

Ryugo, D. K., \&e Winberger, N. M. (1978). Differential plasticity of morphologically distinct neuron populations in the medial geniculate body of the cat during classical conditioning. Behavioral Biology, 22, 275-301

SChIFFMan, K., FUREdy, J. J. (1977). The effect of CS-US contingency variation on GSR and on subjective CS-US relational awareness. Memory \& Cognition, 5, 273-277.

SCHLOSBERG, H. (1937). The relationship between success and the laws of conditioning. Psychological Review, 44, 379-394.

Schneiderman, N., Fuentes, I., * Gormezano, I. (1962). Acquisition and extinction of the classically conditioned eyelid response in the albino rabbit. Science, 136, 650-652.

Schneiderman, N., Vandercar, D. H., Yehle, A. L., Manning, A. A., Golden, T., Schneiderman, E. (1969). Vagal compensatory adjustment: Relationship to heart rate classical conditioning in rabbits. Joumal of Comparative \& Physiological Psychology, 68, 175-183.

Schramm, C. F., Kimmel, H. D. (1970). Resistance to extinction in GSR conditioning following different numbers of postpeak acquisition trials. Joumal of Experimental Psychology, 84, 239-243.

SCHReUrs, B. G. (1989). Classical conditioning of model systems: A behavioral review. Psychobiology, 17, 145-155.

SHEARN, D. (1961). Does the heart learn? Psychological Bulletin, 58 , 452-458.

SIEGEL, S. (1969). Effect of CS habituation on eyelid conditioning. Journal of Comparative \& Physiological Psychology, 68, 245-248.

Siggel, S. (1970). Retention of latent inhibition. Psychonomic Science, 20, 161-162.

Siegel, S., Domun, M. (1971). Backward conditioning as an inhibitory procedure. Leaming and Motivation, 2, 1-11.

Silver, A. I., Greco, T. S. (1975). A comparison of the effects of vicariously instigated classical conditioning and direct classical conditioning procedures. Pavlovian Joumal of Biological Science, 10 , 216-225.

SMrTh, M. C. (1968). CS-US interval and US intensity in classical conditioning of the rabbit's nictitating membrane response. Journal of Comparative \& Physiological Psychology, 66, 679-687.
Smith, M. C., Colgman, S. R., Gormezano, I. (1969). Classical conditioning of the rabbit's nictitating membrane response at backward, simultaneous, and forward CS-US intervals. Joumal of Comparative \& Physiological Psychology, 69, 226-231.

SNYDER, R. E., PAPSDORF, J. D. (1968). The introduction of ITI interpolated stimuli and ISI on classical conditioning of the nictitating membrane response of the rabbit. Psychonomic Science, 12, 191-192.

Soltysik, S. S., Nicholas, T., \& Wilson, W. J. (1984). Postnatal development of respiratory and vocal responses during aversive classical conditioning in cats. Pavlovian Joumal of Biological Science, $19,169-181$

Soltysik, S. S., Wolfe, G., Garcia-Sanchez, J., Nicholas, T (1982). Infantile and adult heart rate pattems in cats during aversive conditioning. Bulletin of the Psychonomic Society, 19, 51-54.

Stava, L. G., Hupka, R. B. (1976). Effects of hypothermia on Pavlovian conditioning in the rabbit: II. Heart rate response. Bulletin of the Psychonomic Society, 7, 246-248.

Stein, M., Luparello, T. J. (1967). The measurement of respiration. In C. C. Brown (Ed.), Methads in psychophysiology (pp. 75 . 94). Baltimore: Williams and Wilkins.

Stewart, M. A., Stern, J. A., Winokur, G., \& Fredman, S. (1961). An analysis of GSR conditioning. Psychological Review, 68, 60-67.

TEYLER, T. J. (1971), Effects of restraint on heart-rate conditioning in rats as a function of US location. Journal of Comparative \& Physiological Psychology, 77, 31-37.

THEWS, G., \& VAUPEL, P. (1985). Autonomic functions in human physiology (M. A. Biederman-Thorson, Trans.) New York: SpringerVerlag.

VANDerCar, D. H., AChneiderman, N. (1967). Interstimulus interval functions in different response systems during classical discrimination conditioning of rabbits. Psychonomic Science, 9, 9-10.

VARDARIS, R. M., \& FitzGerald, R. D. (1969). Effects of partial reinforcement on a classically conditioned eyeblink response in dogs. Journal of Comparative \& Physiological Psychology, 67, 531-534.

VAn Twyver, H. B., KING, R. L. (1969). Classical conditioning of the galvanic skin response in immobilized cats. Psychophysiology, 5, 530-535.

VoIGT, W. H. (1968). Conditioning: The human pupillary response. Perceptual \& Motor Skills, 26, 975-982.

WATson, J. B. (1916). The place of the conditioned reflex in psychology. Psychological Review, 23, 89-116.

Weingerger, N. M. (1982). Effects of conditioned arousal on the auditory system. In A. L. Beckman (Ed.), The neural basis of behavior (pp. 63-91). New York: Spectrum.

Weinberger, N. M., Diamond, D. M., McKenna, T. M. (1984). Initial events in conditioning: Plasticity in the pupillomotor and auditory systems. In G. Lynch, J. L. McGaugh, \& N. M. Weinberger (Eds.), Neurobiology of learning and memory (pp. 197-227). New York: Guilford.

Weinberger, N. M., Hopxins, W., \& Diamond, D. M. (1984). Physiological plasticity of single neurons in auditory cortex of the cat during acquisition of the pupillary conditioned response: I. Primary field (AI). Behavioral Neuroscience, $98,171-188$.

Weinberger, N. M., Oleson, T. D., * Haste, D. (1973). Inhibitory control of conditional pupillary dilation response in the paralyzed cat. Behavioral Biology, 9, 307-316.

Wolach, A. H., Breuning, S. E., Roocaporte, P., \& Solhkhan, N. (1977). Overshadowing and blocking in a goldfish respiratory conditioning situation. Psychological Record, 27, 693-702.

WOODARD, W. T. (1971). Classical respiratory conditioning in the fish: CS intensity. American Joumal of Psychology, 84, 549-554.

WoOdy, C., Yarowsky, P., OWENS, J., Black-Cleworth, P., * Crow, T. (1974). Effect of lesions of cortical motor areas on acquisition of conditioned eye blink in the cat. Joumal of Neurophysiology, 37, 385-394.

YARemko, R. M., Boice, R., * Thompson, R. W. (1969). Classical and avoidance conditioning of the nictitating membrane in frogs (Rana pipiens) and toads (Bufo Americanus). Psychonomic Science, 16, 162-164.

YeHLE, A. (1968). Divergences among rabbit response systems during three-toned classical discrimination conditioning. Joumal of $E_{x}$ perimental Psychology, 77, 468-473. 
Yehle, A., DAuth, G., Schneiderman, N. (1967). Correlates of heart-rate classical conditioning in curarized rabbits. Journal of Comparative \& Physiological Psychology, 64, 98-104.

Yehle, A. L., Spaulding, L. E., LaI, H.-Y. (1970). Classical discrimination conditioning and reversal in the albino rabbit. Psychonomic Science, 20, 187-188.

\section{NOTES}

1. These findings do not imply that the slow responses cannot develop much more rapidly than the values reported in this survey. For example, the use of extremely long ITIs of 24 or $48 \mathrm{~h}$ (rarely employed in conditioning studies) results in the NM CR in 5-10 trials (Levinthal, Tartell, Margolin, \& Fishman, 1985). It is the relative rates of development of the "fast" and "slow" responses which are at issue. Thus, in the case of rapid development of the NM CR, the question is whether or not, for example, the cardiac CR still develops before the NM response develops.

2. Eight of the groups in the survey were trained with a trace conditioning procedure. Because trace procedures can retard conditioning, all of the data were analyzed a second time with these groups elimi- nated. Four GSR, three NM, and one eyelid group were omitted. This resulted in a group of fast CRs (5.86 \pm 0.55 trials to the first $C R)$ and slow (62.7 \pm 11.8 trials) CRs, which were still significantly different from each other $(p \leq .0001)$. Thus, the inclusion of some data from trace conditioning in the overall survey was not responsible for the bimodal distribution of trials to the first $\mathbf{C R}$.

3. Potential alternative data on learning rates might come from studies in which different groups are given various numbers of training trials and in which postlearning CR strength, probability, and so forth, are assessed. However, such data are rare.

4. The idea of a separate mechanism for the acquisition of rapidly acquired emotional CRs is interesting in itself. Animals do seem to be able to associate CSs with the "affective" aspects of a US. For example, if a CS is paired with the omission of food, and if this CS is later presented in compound with a second CS and paired with shock, there will be less conditioned suppression to the second CS (Dickinson, reported in Dickinson \& Dearing, 1979). This is the basic blocking procedure, with food omission replacing the shock in Stage 1. The implication is that shock and omission of food have the same blocking effects on later conditioning; this suggests that the emotional aspects of the US were somehow associated with the CS.

\section{APPENDIX A \\ Learning Rate Data Tables}

In the tables in Appedix A, various abbreviations occur.

In the Subject column: $U$, unrestrained; $R$, restrained; $P$, paralyzed.

In the CS Type column: "W. noise," white noise.

In the Control column: "Sensitiz." means that there was a separate sensitization (unpaired CS and US trials) group. "Sensitiz. WI" means that unpaired CS and US trials were delivered in a within-subject design. "Sensitiz. WI/ND" means that withinsubject sensitization trials were presented, but the data were not illustrated. "Random" means that a separate group received random CS and US presentation.

For conditioned suppression, the ITI data are not presented in Table A2. Sometimes one trial per day was presented, and sometimes the ITI was not reported.

Question marks signify that values were unclear or unreported.

Table A1

Blood Pressure

\begin{tabular}{|c|c|c|c|c|c|c|c|c|c|c|c|}
\hline 1st CR & Subject & CS Type & $\begin{array}{c}\text { CS } \\
\text { Duration } \\
\text { (sec) }\end{array}$ & $\begin{array}{c}\text { CS } \\
\text { Intensity }\end{array}$ & US Type & $\begin{array}{c}\text { US } \\
\text { Duration } \\
\text { (sec) }\end{array}$ & $\begin{array}{c}\text { US } \\
\text { Intensity }\end{array}$ & $\begin{array}{l}1 S \mid \\
(\sec )\end{array}$ & ITI (sec) & Control & Citation \\
\hline $2-10$ & Rabbit (R) & Tone & 4 & 72 & Eyeshock & 1 & $20 \mathrm{~mA}$ & 4 & 120 & Sensitiz. & $\begin{array}{l}\text { Yehle, Dauth, \& } \\
\text { Schneiderman, } 1967\end{array}$ \\
\hline $2-10$ & Rabbit (P) & Tone & 4 & 72 & Eyeshock & 1 & $20 \mathrm{~mA}$ & 4 & 120 & Sensitiz. & $\begin{array}{l}\text { Yehle, Dauth, \& } \\
\text { Schneiderman, } 1967\end{array}$ \\
\hline $2-6$ & Rat (R) & Tone & 6.5 & 85 & $\begin{array}{l}\text { Thoracic } \\
\text { shock }\end{array}$ & 0.500 & $1.3 \mathrm{~mA}$ & 6 & $\bar{x}=200$ & Sensitiz. & $\begin{array}{l}\text { Hoffman \& Fitzgerald, } \\
1978\end{array}$ \\
\hline $2-6$ & Rat (R) & Tone & 6.5 & 85 & $\begin{array}{l}\text { Ammonia } \\
\text { fumes }\end{array}$ & $-2.5-3.5$ & & 6 & $\bar{x}=200$ & Sensitiz. & $\begin{array}{l}\text { Hoffman \& Fitzgerald, } \\
1978\end{array}$ \\
\hline
\end{tabular}


Table A2

Conditioned Suppression

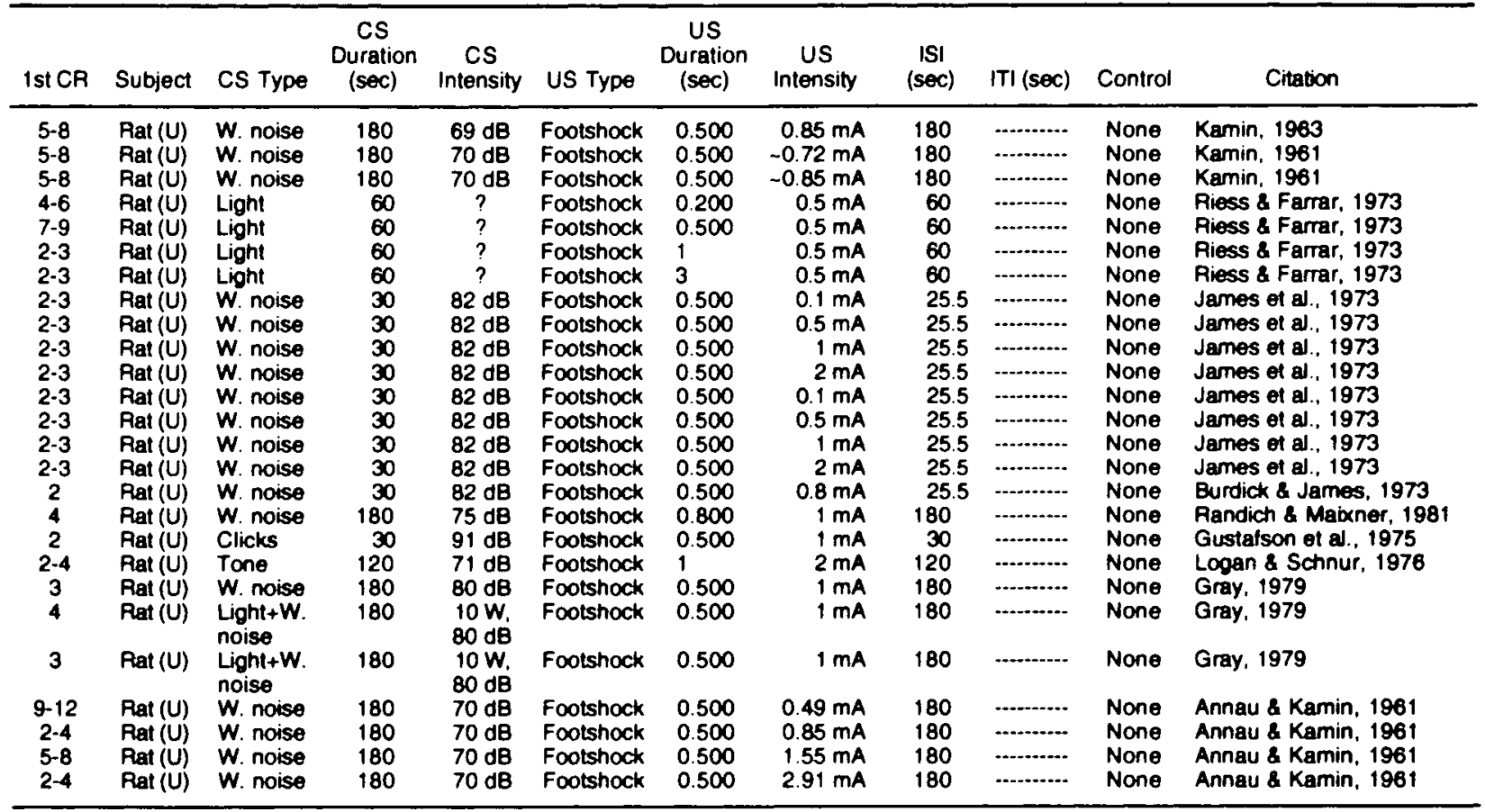

Table A3

Eyelid

\begin{tabular}{|c|c|c|c|c|c|c|c|c|c|c|c|}
\hline 1st CR & Subject & CS Type & $\begin{array}{c}\text { CS } \\
\text { Duration } \\
\text { (sec) }\end{array}$ & $\begin{array}{c}\text { CS } \\
\text { Intensity }\end{array}$ & US Type & $\begin{array}{l}\text { US } \\
\text { Duration } \\
\text { (sec) }\end{array}$ & $\begin{array}{c}\text { US } \\
\text { Intensity }\end{array}$ & $\begin{array}{c}|S| \\
(s e c)\end{array}$ & $\mathrm{ITI}(\mathrm{sec})$ & Control & Citation \\
\hline $41-80$ & Rabbit (R) & Tone & 0.500 & $?$ & $\begin{array}{l}\text { Cheek- } \\
\text { shock }\end{array}$ & -0.005 & $?$ & 0.400 & 60 & None & Frey \& Butler, 1977 \\
\hline $41-60$ & Rabbit (A) & Tone & 0.550 & $80 \mathrm{~dB}$ & $\begin{array}{l}\text { Choek- } \\
\text { shock }\end{array}$ & 0.050 & $3.5 \mathrm{~mA}$ & 0.500 & 180 & None & Frey \& Butler, 1973 \\
\hline $21-40$ & Rabbit (P) & Tone & 0.600 & $80 \mathrm{~dB}$ & $\begin{array}{l}\text { Cheok- } \\
\text { shock }\end{array}$ & 0.100 & $3.5 \mathrm{~mA}$ & 0.500 & 180 & None & Frey \& Butler. 1973 \\
\hline $21-40$ & Rabbit (R) & Tone & 0.700 & $80 \mathrm{~dB}$ & $\begin{array}{l}\text { Cheek- } \\
\text { shock }\end{array}$ & 0.200 & $3.5 \mathrm{~mA}$ & 0.500 & 180 & None & Frey \& Butior, 1973 \\
\hline $\begin{array}{l}101-200 \\
301-400\end{array}$ & $\begin{array}{l}\text { Rabbit (R) } \\
\text { Rabbit (R) }\end{array}$ & $\begin{array}{l}\text { Tone } \\
\text { Light }\end{array}$ & $\begin{array}{l}0.400 \\
0.400\end{array}$ & $\begin{array}{c}70 \mathrm{~dB} \\
?\end{array}$ & $\begin{array}{l}\text { Airpuff } \\
\text { Airpuff }\end{array}$ & $\begin{array}{l}0.200 \\
0.200\end{array}$ & $?$ & $\begin{array}{l}0.400 \\
0.400\end{array}$ & $\begin{array}{l}60 \\
60\end{array}$ & $\begin{array}{l}\text { None } \\
\text { None }\end{array}$ & $\begin{array}{l}\text { Gutman of al., } 1972 \\
\text { Gutman of al., } 1972\end{array}$ \\
\hline $2-20$ & $\operatorname{Dog}(\mathrm{R})$ & Tone & 0.600 & $?$ & Airpuff & 0.100 & 2 psi & 0.500 & $\bar{x}=45$ & Sensitiz. & $\begin{array}{l}\text { Vardaris } 8 \\
\text { Fitzgerald, } 1960\end{array}$ \\
\hline $2 \cdot 25$ & Rabbit (R) & Tone & 0.500 & $75 \mathrm{~dB}$ & Eyeshock & 0.040 & $?$ & 0.500 & $\bar{x}=60$ & None & Siegel, 1969 \\
\hline $361-540$ & Cat (R) & Click & 0.001 & $70 \mathrm{~dB}$ & $\begin{array}{l}\text { Glabellar } \\
\text { tap }\end{array}$ & $?$ & $?$ & 0.400 & 10 & Random & Woody et a., 1974 \\
\hline $26-50$ & Rabbit (R) & Tone & 0.500 & $82 \mathrm{~dB}$ & Eyeshock & 0.100 & $200 \mathrm{~V}$ & 0.500 & $\bar{x}=60$ & None & Siegel, 1970 \\
\hline $26-50$ & Rabbit (R) & Tone & 0.500 & $82 \mathrm{~dB}$ & Eyeshock & 0.100 & $200 \mathrm{~V}$ & 0.500 & $\bar{x}=60$ & None & Siegel, 1970 \\
\hline $26-50$ & Rabbit (R) & Tone & $?$ & $76 \mathrm{~dB}$ & $\begin{array}{l}\text { Cheek- } \\
\text { shock }\end{array}$ & 0.100 & $3.6 \mathrm{~mA}$ & 0.250 & $\bar{x}=300$ & None & Frey 8 Ross, 1968 \\
\hline $2-25$ & Pabbit (R) & Tone & $?$ & $76 \mathrm{~dB}$ & $\begin{array}{l}\text { Cheek- } \\
\text { shock }\end{array}$ & 0.100 & $3.6 \mathrm{~mA}$ & 0.400 & $\bar{x}=300$ & None & Frey \& Ross, 1968 \\
\hline $51-75$ & Rabbit (R) & Tone & $?$ & $76 \mathrm{~dB}$ & $\begin{array}{l}\text { Cheek- } \\
\text { shock }\end{array}$ & 0.100 & $3.6 \mathrm{~mA}$ & 0.600 & $\bar{x}=300$ & None & Frey \& Ross, 1988 \\
\hline $51-75$ & Rabbit (R) & Tone & $?$ & $76 \mathrm{~dB}$ & $\begin{array}{l}\text { Cheek- } \\
\text { shock }\end{array}$ & 0.100 & $3.6 \mathrm{~mA}$ & 1 & $\bar{x}=300$ & None & Frey $\&$ Ross, 1968 \\
\hline $176-200$ & Rabbit (R) & Tone & $?$ & $76 \mathrm{~dB}$ & $\begin{array}{l}\text { Cheek- } \\
\text { shock }\end{array}$ & 0.100 & $3.6 \mathrm{~mA}$ & 2 & $\bar{x}=300$ & None & Frey \& Ross, 1968 \\
\hline $56-116$ & $\operatorname{Dog}(R)$ & Light & $?$ & $150 W$ & Airpuff & $?$ & $?$ & 0.375 & $20-40$ & $\begin{array}{l}\text { Sensitiz. } \\
\text { WI/ND }\end{array}$ & Hilgard \& Marquis, 1935 \\
\hline $26-50$ & Rabbit (R) & Tone & 0.500 & $82 \mathrm{~dB}$ & Eyeshock & 0.100 & $200 \mathrm{~V}$ & 0.500 & $?$ & None & Siegel \& Domjan, 1971 \\
\hline
\end{tabular}


Table A4

Flexion (Limb/Tail)

\begin{tabular}{|c|c|c|c|c|c|c|c|c|c|c|c|}
\hline ist CR & Subject & CS Type & $\begin{array}{c}\text { CS } \\
\text { Duration } \\
\text { (sec) }\end{array}$ & $\begin{array}{c}\text { CS } \\
\text { Intensity }\end{array}$ & US Type & $\begin{array}{c}\text { US } \\
\text { Duration } \\
\text { (sec) }\end{array}$ & $\begin{array}{c}\text { US } \\
\text { Intensity }\end{array}$ & $\begin{array}{c}|S| \\
(\mathrm{sec})\end{array}$ & ITI (sec) & Control & Citation \\
\hline $201-300$ & Rat (R) & Tone & 0.500 & $?$ & Footshock & 0.250 & $0.5 \mathrm{~mA}$ & 0.500 & 45 & Random & Ginn et al., 1983 \\
\hline $126-150$ & Cat (R) & Light & $?$ & $?$ & Footshock & $?$ & $3 \mathrm{~mA}$ & 0.500 & $\bar{x}=15$ & $\begin{array}{l}\text { Sensitiz. } \\
\text { W }\end{array}$ & $\begin{array}{l}\text { O'Brien \& } \\
\text { Packham, } 1973\end{array}$ \\
\hline $2-25$ & Cat (R) & Light & $?$ & $?$ & Footshock & $?$ & $8 \mathrm{~mA}$ & 0.500 & $\bar{x}=15$ & $\begin{array}{l}\text { Sensitiz. } \\
\text { W }\end{array}$ & $\begin{array}{l}\text { O'Brien \& } \\
\text { Packham, } 1973\end{array}$ \\
\hline $2-10$ & Lizard (R) & $\begin{array}{l}\text { Light+ } \\
\text { tone }\end{array}$ & 11 & $?$ & Legshock & 1 & $0.1 \mathrm{~mA}$ & 10 & 105 & None & $\begin{array}{l}\text { Davidson \& Richardson, } \\
1970\end{array}$ \\
\hline $2-10$ & Cat $(\mathrm{R})$ & W. noise & 0.600 & $80 \mathrm{~dB}$ & Footshock & 0.100 & $150 \mathrm{~V}$ & 0.500 & 75 & None & Plumer et al., 1973 \\
\hline $401-500$ & Rat (R) & W. noise & 1 & $?$ & Tailshock & 0.500 & $1.6 \mathrm{~mA}$ & 1 & $?$ & Random & Miller et al., 1981 \\
\hline 2.50 & Rat (R) & Tone & 1 & $72 \mathrm{~dB}$ & Tailshock & 0.175 & $1.5 \mathrm{~mA}$ & 1 & $\bar{x}=60$ & Sensitiz. & Chacto \& Lubow, 1967 \\
\hline $2-4$ & $\operatorname{Dog}(R)$ & Tone & 1 & $80 \mathrm{~dB}$ & Pawshock & 0.100 & $1.7 \mathrm{~mA}$ & 0.900 & $?$ & None & Bames, 1956 \\
\hline $2-4$ & $\operatorname{Dog}(\mathbf{R})$ & Tone & 6 & $80 \mathrm{~dB}$ & Pawshock & 0.100 & $1.7 \mathrm{~mA}$ & 0.900 & $?$ & None & Bames, 1956 \\
\hline $2-4$ & $\operatorname{Dog}(R)$ & Tone & 16 & $80 \mathrm{~dB}$ & Pawshock & 0.100 & $1.7 \mathrm{~mA}$ & 0.900 & $?$ & None & Bames, 1956 \\
\hline $2-4$ & $\operatorname{Dog}(R)$ & Tone & 31 & $80 \mathrm{~dB}$ & Pawshock & 0.100 & $1.7 \mathrm{~mA}$ & 0.900 & $?$ & None & Bames, 1956 \\
\hline $5-8$ & $\operatorname{Dog}(R)$ & Tone & 1 & $60 \mathrm{~dB}$ & Pawshock & 0.100 & $1.7 \mathrm{~mA}$ & 0.900 & $?$ & None & Bames, 1956 \\
\hline $2-4$ & $\operatorname{Dog}(R)$ & Tone & 6 & $60 \mathrm{~dB}$ & Pawshock & 0.100 & $1.7 \mathrm{~mA}$ & 0.900 & $?$ & None & Bames, 1956 \\
\hline $5-8$ & $\operatorname{Dog}(\mathrm{R})$ & Tone & 16 & $60 \mathrm{~dB}$ & Pawshock & 0.100 & $1.7 \mathrm{~mA}$ & 0.900 & $?$ & None & Bames, 1956 \\
\hline $13-16$ & $\operatorname{Dog}(R)$ & Tone & 1 & $60 \mathrm{~dB}$ & Pawshock & 0.100 & $1.7 \mathrm{~mA}$ & 0.900 & $?$ & None & Bames, 1956 \\
\hline
\end{tabular}

Table A5

Galvanic Skin Response

\begin{tabular}{|c|c|c|c|c|c|c|c|c|c|c|c|}
\hline 1st CR & Subject & $\begin{array}{l}\text { CS } \\
\text { Type }\end{array}$ & $\begin{array}{c}\text { CS } \\
\text { Duration } \\
\text { (sec) }\end{array}$ & $\begin{array}{c}\text { CS } \\
\text { Intensity }\end{array}$ & US Type & $\begin{array}{l}\text { US } \\
\text { Duration } \\
\text { (sec) }\end{array}$ & $\begin{array}{c}\text { US } \\
\text { Intensity }\end{array}$ & $\underset{(\sec )}{I S \mid}$ & $\mathrm{ITI}(\mathrm{sec})$ & Control & Citation \\
\hline 2 & Human (U) & Light & 0.500 & $7 w$ & $\begin{array}{l}\text { Finger } \\
\text { shock }\end{array}$ & 0.500 & $1.5 \mathrm{~V}$ & 10 & 240 & None & Golin \& Golin, 1966 \\
\hline 2 & Human (U) & Tone & 8 & $74 \mathrm{~dB}$ & $\begin{array}{l}\text { Finger } \\
\text { shock }\end{array}$ & 0.200 & $?$ & 8 & $\bar{x}=45$ & Sensitiz. & Prokasy \& Ebel, 1967 \\
\hline 2 & Human (U) & Tone & 8 & $100 \mathrm{~dB}$ & $\begin{array}{l}\text { Finger } \\
\text { shock }\end{array}$ & 0.200 & $?$ & 8 & $\bar{x}=45$ & Sensitiz. & Prokasy \& Ebel, 1967 \\
\hline $2-5$ & Human (U) & Tone & 5 & $?$ & Shock & 0.300 & $2.5 \mathrm{~mA}$ & 5 & $?$ & Sensitiz. & $\begin{array}{l}\text { Schiffman \& Furedy, } \\
1977\end{array}$ \\
\hline 2 & Human (U) & Tone & 5 & $39 \mathrm{~dB}$ & Amshock & 0.100 & $4 \mathrm{~mA}$ & 5 & $?$ & $\begin{array}{l}\text { Sensitiz. } \\
\text { W/ND }\end{array}$ & Silver \& Greco, 1975 \\
\hline 2 & Human (U) & Light & 1 & $?$ & Armshock & 0.100 & $4.3 \mathrm{~mA}$ & 4.9 & $\bar{x}=40$ & $\begin{array}{l}\text { Sensitiz. } \\
\text { W/ND }\end{array}$ & Kimmel et al., 1969 \\
\hline 2 & Human (U) & Light & 1 & $?$ & Armshock & 0.100 & $8.6 \mathrm{~mA}$ & 4.9 & $\bar{x}=40$ & $\begin{array}{l}\text { Sensitiz. } \\
\text { W/ND }\end{array}$ & Kimmel et al., 1969 \\
\hline 2 & Human (U) & Tone & 5 & $40 \mathrm{~dB}$ & Armshock & 0.100 & $4 \mathrm{~mA}$ & 4.9 & $\bar{x}=50$ & Sensitiz. & $\begin{array}{l}\text { Schramm } \\
\text { Kimmel, } 1970\end{array}$ \\
\hline $2-3$ & Human (U) & $\begin{array}{l}\text { Light+ } \\
\text { tone }\end{array}$ & 0.600 & $\begin{array}{l}\text { Tone }= \\
70 \mathrm{~dB}\end{array}$ & $\begin{array}{l}\text { Finger } \\
\text { shock }\end{array}$ & 0.100 & $3.5 \mathrm{~mA}$ & 0.500 & $?$ & Sensitiz. & Morrow et al., 1970 \\
\hline $2-6$ & Rat (R) & Clicks & 5 & $75 \mathrm{~dB}$ & Tailshock & 0.300 & $0.5 \mathrm{~mA}$ & 5 & $\bar{x}=150$ & Sensitiz. & $\begin{array}{l}\text { Holdstock \& } \\
\text { Schwartzbaum, } 1965\end{array}$ \\
\hline $2-6$ & Rat (R) & Clicks & 5 & $75 \mathrm{~dB}$ & Tailshock & 0.300 & $1.5 \mathrm{~mA}$ & 5 & $\bar{x}=150$ & Sensitiz. & $\begin{array}{l}\text { Holdstock \& } \\
\text { Schwartzbaum, } 1965\end{array}$ \\
\hline $2-4$ & Human (U) & Tone & 0.050 & $90 \mathrm{~dB}$ & Airpuff & 0.050 & 3 psi & 0.400 & $\bar{x}=30$ & $\begin{array}{l}\text { Sensitiz. } \\
\text { W/ND }\end{array}$ & Champion, 1962 \\
\hline $2-5$ & Cat (P) & Tone & 5 & $88 \mathrm{~dB}$ & $\begin{array}{l}\text { Flank } \\
\text { shock }\end{array}$ & 0.100 & $60 \mathrm{~V}$ & 4.9 & $\bar{X}=80$ & Sensitiz. & $\begin{array}{l}\text { Van Twyer \& King, } \\
1969\end{array}$ \\
\hline
\end{tabular}


Table A6

Heart Rate

\begin{tabular}{|c|c|c|c|c|c|c|c|c|c|c|c|}
\hline 1st CR & Subject & CS Type & $\begin{array}{c}\text { CS } \\
\text { Duration } \\
\text { (sec) }\end{array}$ & $\begin{array}{c}\text { CS } \\
\text { Intensity }\end{array}$ & US Type & $\begin{array}{l}\text { US } \\
\text { Duration } \\
\text { (sec) }\end{array}$ & $\begin{array}{c}\text { US } \\
\text { Intensity }\end{array}$ & $\begin{array}{c}|S| \\
(\sec )\end{array}$ & ITI (sec) & Control & Citation \\
\hline $2 \cdot 10$ & Lizard (R) & $\begin{array}{l}\text { Light + } \\
\text { tone }\end{array}$ & 11 & $?$ & Legshock & $\uparrow$ & $0.1 \mathrm{~mA}$ & 10 & 105 & None & $\begin{array}{l}\text { Davidson \& } \\
\text { Richarotson, } 1970\end{array}$ \\
\hline $2-20$ & Pigeon (R) & Light & 6.5 & $?$ & Footshock & 0.500 & $?$ & 6 & $\bar{x}=444$ & None & $\begin{array}{l}\text { Durkovic \& Cohen, } \\
1969\end{array}$ \\
\hline $2-5$ & Rabbit (R) & Tone & 2.25 & $70 \mathrm{~dB}$ & Eyeshock & 0.050 & $2 \mathrm{~mA}$ & 2.25 & $\bar{x}=180$ & None & $\begin{array}{l}\text { Stava \& Hupka, } \\
1976\end{array}$ \\
\hline $2 \cdot 20$ & Pigeon (R) & Light & 6.5 & $?$ & Footshock & 0.500 & $?$ & 6 & $\bar{x}=444$ & Sensitiz. & Cohen \& Pitts, 1968 \\
\hline $2-26$ & Rat (U) & Light & 6 & $?$ & Footshock & 0.500 & $?$ & 6 & $?$ & None & $\begin{array}{l}\text { Bloch-Rojas et al., } \\
1964\end{array}$ \\
\hline 2 & $\operatorname{Dog}(\mathbf{R})$ & Tone & 13 & $80 \mathrm{~dB}$ & Legshock & 3 & $9.9 \mathrm{~mA}$ & 10 & $\bar{x}=210$ & None & Fitzgerald, 1966 \\
\hline $3-4$ & $\operatorname{Dog}(R)$ & Tone & 13 & $80 \mathrm{~dB}$ & Legshock & 3 & $9.9 \mathrm{~mA}$ & 10 & $\bar{x}=390$ & None & Fitzgerald, 1966 \\
\hline $3-4$ & $\operatorname{Dog}(\mathrm{R})$ & Tone & 13 & $80 \mathrm{~dB}$ & Legshock & 3 & $9.9 \mathrm{~mA}$ & 10 & $\bar{x}=390$ & Sensitiz & Fitzgerald et al. 1966 \\
\hline $2-9$ & Rabbit (R) & Tone & 4 & $72 \mathrm{~dB}$ & Eyeshock & 1 & $20 \mathrm{~mA}$ & 4 & 120 & Sensitiz. & Yehle et al., 1967 \\
\hline $\begin{array}{l}2-9 \\
2-10\end{array}$ & $\begin{array}{l}\text { Rabbit (P) } \\
\text { Guinea pig } \\
\text { (A) }\end{array}$ & $\begin{array}{l}\text { Tone } \\
\text { Tone }\end{array}$ & $\begin{array}{r}4 \\
10\end{array}$ & $\begin{array}{r}72 \mathrm{~dB} \\
0 \mathrm{~dB}\end{array}$ & $\begin{array}{l}\text { Eyeshock } \\
\text { Thoracic } \\
\text { shock }\end{array}$ & $\begin{array}{l}1 \\
5\end{array}$ & $\begin{array}{l}20 \mathrm{~mA} \\
2.5 \mathrm{~mA}\end{array}$ & $\begin{array}{r}4 \\
10\end{array}$ & $\begin{array}{c}120 \\
\bar{x}=147.5\end{array}$ & $\begin{array}{l}\text { Sensitiz. } \\
\text { Sensitiz. }\end{array}$ & $\begin{array}{l}\text { Yehle et al., } 1967 \\
\text { Anderson, } 1972\end{array}$ \\
\hline $21 \cdot 30$ & Pigeon (P) & Light & 6 & $?$ & Footshock & 0.500 & $1.5 \mathrm{~mA}$ & 6 & $\bar{x}=222$ & None & Gold \& Cohen, 1981 \\
\hline $21-30$ & Pigeon (R) & Light & 6 & $?$ & Footshock & 0.500 & $1.5 \mathrm{~mA}$ & 6 & $\bar{x}=222$ & Sensitiz. & Gold \& Cohen, 1981 \\
\hline $2 \cdot 20$ & Pigeon (R) & Light & 6.5 & $?$ & Footshock & 0.500 & 3-7 V & 6 & $\bar{x}=444$ & Sensitiz. & $\begin{array}{l}\text { Cohen \& Durkovic, } \\
1966\end{array}$ \\
\hline $2-8$ & Rat (R) & Clicks & 5 & $75 \mathrm{~dB}$ & Tailshock & 3 & $0.5 \mathrm{~mA}$ & 5 & $\bar{x}=150$ & Sensitiz. & $\begin{array}{l}\text { Holdstock \& } \\
\text { Schwartzbaum, } 1965\end{array}$ \\
\hline $2-8$ & Rat (R) & Clicks & 5 & $75 \mathrm{~dB}$ & Tailshock & 0.300 & $1.5 \mathrm{~mA}$ & 5 & $\bar{x}=150$ & Sensitiz. & $\begin{array}{l}\text { Holdstock \& } \\
\text { Schwartzbaum, } 1965\end{array}$ \\
\hline $2-6$ & Rat $(A)$ & Tone & 6.5 & $85 \mathrm{~dB}$ & $\begin{array}{l}\text { Thoracic } \\
\text { shock }\end{array}$ & 0.500 & $1.3 \mathrm{~mA}$ & 6 & $\bar{x}=200$ & Sensitiz. & $\begin{array}{l}\text { Hoffman \& Fitzgerald. } \\
1978\end{array}$ \\
\hline $2-6$ & Rat (R) & Tone & 6.5 & $85 \mathrm{~dB}$ & $\begin{array}{l}\text { Ammonia } \\
\text { fumes }\end{array}$ & $\begin{array}{l}-2.5 \\
3.5 \sec \end{array}$ & & 6 & $\bar{x}=200$ & Sensitiz. & $\begin{array}{l}\text { Hoffman \& Fitzgerald, } \\
1978\end{array}$ \\
\hline
\end{tabular}

Table A7

Nictitating Membrane

\begin{tabular}{|c|c|c|c|c|c|c|c|c|c|c|c|}
\hline 1 st CA & Subject & $\begin{array}{l}\text { CS } \\
\text { Type }\end{array}$ & $\begin{array}{c}\text { CS } \\
\text { Duration } \\
\text { (sec) }\end{array}$ & $\begin{array}{c}\text { CS } \\
\text { Intensity }\end{array}$ & US Type & $\begin{array}{l}\text { US } \\
\text { Duration } \\
\text { (sec) }\end{array}$ & $\begin{array}{l}\text { US } \\
\text { Intensity }\end{array}$ & $\begin{array}{c}|S| \\
(\mathrm{sec})\end{array}$ & ITI (sec) & Control & Citation \\
\hline $64-72$ & Rabbit (R) & Tone & 0.350 & $85 \mathrm{~dB}$ & Airputf & 0.100 & $210 \mathrm{~g} / \mathrm{cm}$ & 0.250 & $\bar{x}=60$ & Sensitiz. & Berger \& Thompson, 1978 \\
\hline $\begin{array}{l}21-40 \\
21-40 \\
51-150 \\
51-150 \\
51-150 \\
11-20\end{array}$ & $\begin{array}{l}\text { Rabbit (R) } \\
\text { Rabbit (R) } \\
\text { Rabbit (R) } \\
\text { Rabbit (R) } \\
\text { Rabbit (R) } \\
\text { Shark (R) }\end{array}$ & $\begin{array}{l}\text { Tone } \\
\text { Tone } \\
\text { Tone } \\
\text { Tone } \\
\text { Tone } \\
\text { Light }\end{array}$ & $\begin{array}{l}0.500 \\
0.500 \\
0.350 \\
0.350 \\
0.350 \\
0.500\end{array}$ & $\begin{array}{l}98 \mathrm{~dB} \\
98 \mathrm{~dB} \\
75 \mathrm{~dB} \\
75 \mathrm{~dB} \\
75 \mathrm{~dB} \\
671 \mathrm{fc}\end{array}$ & $\begin{array}{l}\text { Eyeshock } \\
\text { Eyeshock } \\
\text { Eyeshock } \\
\text { Eyeshock } \\
\text { Eyeshock } \\
\text { Headshock }\end{array}$ & $\begin{array}{l}0.200 \\
0.200 \\
0.050 \\
0.050 \\
0.050 \\
0.100\end{array}$ & $\begin{array}{c}3 \mathrm{~mA} \\
3 \mathrm{~mA} \\
3 \mathrm{~mA} \\
3 \mathrm{~mA} \\
3 \mathrm{~mA} \\
10-100 \\
\mathrm{~mA}\end{array}$ & $\begin{array}{l}0.300 \\
0.300 \\
0.350 \\
0.350 \\
0.350 \\
4\end{array}$ & $\begin{array}{r}55 \\
55 \\
30 \\
30 \\
30 \\
\bar{X}=30\end{array}$ & $\begin{array}{l}\text { None } \\
\text { None } \\
\text { None } \\
\text { None } \\
\text { None } \\
\text { None }\end{array}$ & $\begin{array}{l}\text { Plotkin \& Oakley, } 1975 \\
\text { Plotkin \& Oakley, } 1975 \\
\text { Mis \& Moore, } 1973 \\
\text { Mis \& Moore, } 1973 \\
\text { Mis \& Moore, } 1973 \\
\text { Gruber \& Schneiderman, } \\
1975\end{array}$ \\
\hline $\begin{array}{l}16-30 \\
16-30 \\
21-30 \\
31-40 \\
91-180\end{array}$ & $\begin{array}{l}\text { Rabbit (R) } \\
\text { Rabbit (R) } \\
\text { Rabbit (R) } \\
\text { Rabbit (R) } \\
\text { Rabbit (R) }\end{array}$ & $\begin{array}{l}\text { Tone } \\
\text { Tone } \\
\text { Tone } \\
\text { Tone } \\
\text { Tone }\end{array}$ & $\begin{array}{l}0.450 \\
0.850 \\
0.250 \\
0.250 \\
\quad ?\end{array}$ & $\begin{array}{l}93 \mathrm{~dB} \\
93 \mathrm{~dB} \\
70 \mathrm{~dB} \\
70 \mathrm{~dB} \\
86 \mathrm{~dB}\end{array}$ & $\begin{array}{l}\text { Eyeshock } \\
\text { Eyeshock } \\
\text { Eyeshock } \\
\text { Eyeshock } \\
\text { Eyeshock }\end{array}$ & $\begin{array}{l}0.100 \\
0.100 \\
0.050 \\
0.050 \\
0.050\end{array}$ & $\begin{array}{c}3 \mathrm{~mA} \\
3 \mathrm{~mA} \\
? \\
? \\
4 \mathrm{~mA}\end{array}$ & $\begin{array}{l}0.350 \\
0.350 \\
0.750 \\
0.250 \\
0.800\end{array}$ & $\begin{array}{c}60 \\
60 \\
100 \\
200 \\
\bar{X}=184\end{array}$ & $\begin{array}{l}\text { None } \\
\text { None } \\
\text { None } \\
\text { None } \\
\text { None }\end{array}$ & $\begin{array}{l}\text { Snyder \& Papsdort, } 1968 \\
\text { Snyder \& Papsdort, } 1968 \\
\text { Grevert \& Moore, } 1970 \\
\text { Grevert \& Moore, } 1970 \\
\text { Mitchell, } 1973\end{array}$ \\
\hline $\begin{array}{c}2-30 \\
101-200 \\
201-300 \\
21-30\end{array}$ & $\begin{array}{l}\text { Toad (R) } \\
\text { Rabbit (R) } \\
\text { Rabbit (R) } \\
\text { Rabbit (R) }\end{array}$ & $\begin{array}{l}\text { Tactile } \\
\text { Tone } \\
\text { Tone } \\
\text { Tone }\end{array}$ & $\begin{array}{l}2 \\
0.500 \\
0.450 \\
0.310\end{array}$ & $\begin{array}{l}85 \mathrm{~dB} \\
85 \mathrm{~dB} \\
80 \mathrm{~dB}\end{array}$ & $\begin{array}{l}\text { Tactile } \\
\text { Eyeshock } \\
\text { Eyeshock } \\
\text { Eyeshock }\end{array}$ & $\begin{array}{l}0.500 \\
0.050 \\
0.050 \\
0.050\end{array}$ & $\begin{array}{l}2 \mathrm{~mA} \\
2 \mathrm{~mA} \\
4 \mathrm{~mA}\end{array}$ & $\begin{array}{l}2 \\
0.450 \\
0.950 \\
0.260\end{array}$ & $\begin{aligned} & ? \\
& 30 \\
& 30 \\
& \bar{x}= 30\end{aligned}$ & $\begin{array}{l}\text { Sensitiz. } \\
\text { None } \\
\text { None } \\
\text { None }\end{array}$ & $\begin{array}{l}\text { Yaremko et al., } 1969 \\
\text { Graves \& Solomon, } 1985 \\
\text { Graves \& Solomon, } 1985 \\
\text { Gormezano \& Coleman, } \\
1975\end{array}$ \\
\hline $11-20$ & Rabbit (R) & Tone & 0.310 & $80 \mathrm{~dB}$ & Eyeshock & 0.050 & $4 \mathrm{~mA}$ & 0.260 & $\bar{x}=60$ & None & $\begin{array}{l}\text { Gormezano \& Coleman, } \\
1975\end{array}$ \\
\hline $\begin{array}{l}21-30 \\
31-40\end{array}$ & $\begin{array}{l}\text { Rabbit }(R) \\
\text { Rabbit }(R)\end{array}$ & $\begin{array}{l}\text { Tone } \\
\text { Tonet } \\
\text { buzzer }\end{array}$ & $\begin{array}{l}0.250 \\
0.340\end{array}$ & $\begin{array}{l}85 \mathrm{~dB} \\
95 \mathrm{~dB}\end{array}$ & $\begin{array}{l}\text { Eyeshock } \\
\text { Eyeshock }\end{array}$ & $\begin{array}{l}0.010 \\
0.001\end{array}$ & $\begin{array}{c}10 \mathrm{~mA} \\
?\end{array}$ & $\begin{array}{l}0.250 \\
0.250\end{array}$ & $\begin{array}{r}60 \\
120\end{array}$ & $\begin{array}{l}\text { None } \\
\text { None }\end{array}$ & $\begin{array}{l}\text { Leonard et al., } 1972 \\
\text { Leonard \& Theios, } 1967\end{array}$ \\
\hline $71-140$ & Rabbit (R) & Tone & 0.600 & $72 \mathrm{~dB}$ & Airpuff & 0.100 & $80 \mathrm{~mm}$ & 0.500 & $\bar{x}=20$ & Random & Gormezano et al., 1962 \\
\hline $\begin{array}{l}11-15 \\
26-30\end{array}$ & $\begin{array}{l}\text { Rabbit (R) } \\
\text { Rabbit (R) }\end{array}$ & $\begin{array}{l}\text { Tone } \\
\text { Tone }\end{array}$ & $\begin{array}{l}0.400 \\
0.400\end{array}$ & $\begin{array}{l}92 \mathrm{~dB} \\
92 \mathrm{~dB}\end{array}$ & $\begin{array}{l}\text { Eyeshock } \\
\text { Eyeshock }\end{array}$ & $\begin{array}{l}0.050 \\
0.050\end{array}$ & $\begin{array}{l}3 \mathrm{~mA} \\
3 \mathrm{~mA}\end{array}$ & $\begin{array}{l}0.400 \\
0.400\end{array}$ & $\begin{array}{l}\text { N.A. } \\
\bar{X}=60\end{array}$ & $\begin{array}{l}\text { None } \\
\text { None }\end{array}$ & $\begin{array}{l}\text { Kehoe \& Gomezano, } 1974 \\
\text { Kehoe \& Gomezano, } 1974\end{array}$ \\
\hline $26-30$ & Rabbit (R) & Tone & 0.400 & $92 \mathrm{~dB}$ & Eyeshock & 0.050 & $3 \mathrm{~mA}$ & 0.400 & $\bar{x}=60$ & None & Kehoe \& Gomezano, 1974 \\
\hline $36-40$ & Rabbit (R) & Tone & 0.400 & $92 \mathrm{~dB}$ & Eyeshock & 0.050 & $3 \mathrm{~mA}$ & 0.400 & $\bar{x}=60$ & None & Kehoe \& Gomezano, 1974 \\
\hline
\end{tabular}


Table A8

Pupil

\begin{tabular}{|c|c|c|c|c|c|c|c|c|c|c|c|}
\hline 1st CR & Subject & CS Type & $\begin{array}{c}\text { CS } \\
\text { Duration } \\
\text { (sec) }\end{array}$ & $\begin{array}{c}\text { CS } \\
\text { Intensity }\end{array}$ & US Type & $\begin{array}{c}\text { US } \\
\text { Duration } \\
\text { (sec) }\end{array}$ & $\begin{array}{c}\text { US } \\
\text { Intensity }\end{array}$ & $\begin{array}{l}\text { ISI } \\
(\mathrm{sec})\end{array}$ & ITI (sec) & Control & Citation \\
\hline $5-10$ & Cat (R) & Tone & 3.5 & $55 \mathrm{~dB}$ & $\begin{array}{l}\text { Shock+ } \\
\text { light off }\end{array}$ & Shock: 2 & Shock: $4 \mathrm{~V}$ & 1.5 & $\bar{x}=60$ & None & Gerall \& Obrist, 1962 \\
\hline $11-15$ & Cat $(P)$ & W. noise & 2 & $56 \mathrm{~dB}$ & Footshock & 0.005 & $10-50 \mathrm{~V}$ & 1.5 & $?$ & $\begin{array}{l}\text { Sensitiz. } \\
\text { W }\end{array}$ & Oleson et al., 1972 \\
\hline $6-10$ & Cat $(P)$ & $\begin{array}{l}\text { Tone or } \\
\text { W. noise }\end{array}$ & 1 & $70-85 \mathrm{~dB}$ & $\begin{array}{l}\text { Forelimb } \\
\text { shock }\end{array}$ & 0.375 & $2-9 \mathrm{~mA}$ & 1 & $\bar{x}=60$ & $\begin{array}{l}\text { Sensitiz. } \\
\text { W }\end{array}$ & Weinberger et al., 1984 \\
\hline $6-10$ & Cat $(P)$ & $\begin{array}{l}\text { Tone or } \\
\text { W. noise }\end{array}$ & 1 & $70-80 \mathrm{~dB}$ & $\begin{array}{l}\text { Forelimb } \\
\text { shock }\end{array}$ & 0.375 & $2-9 \mathrm{~mA}$ & 1 & $\bar{x}=60$ & $\begin{array}{l}\text { Sensitiz. } \\
\text { W }\end{array}$ & $\begin{array}{l}\text { Diamond \& Weinberger, } \\
1984\end{array}$ \\
\hline 18 & Cat $(P)$ & W. noise & 1 & $75 \mathrm{~dB}$ & $\begin{array}{l}\text { Forelimb } \\
\text { shock }\end{array}$ & 0.500 & $20-25 \mathrm{~V}$ & 1 & $\bar{x}=60$ & $\begin{array}{l}\text { Sensitiz. } \\
W\end{array}$ & $\begin{array}{l}\text { Ryugo \& Weinberger, } \\
1978\end{array}$ \\
\hline $2-5$ & Cal $(\mathbf{P})$ & W. noise & 1.5 & $64-98 \mathrm{~dB}$ & $\begin{array}{l}\text { Forelimb } \\
\text { shock }\end{array}$ & 0.500 & $25 \mathrm{~V}$ & 1.5 & $\bar{x}=90$ & None & Weinberger et al., 1973 \\
\hline 2.5 & Cat $(P)$ & W. noise & 1 & $85 \mathrm{~dB}$ & $\begin{array}{l}\text { Forelimb } \\
\text { shock }\end{array}$ & 0.500 & $25-30 \mathrm{~V}$ & 1 & $\bar{x}=60$ & $\begin{array}{l}\text { Sensitiz. } \\
\text { W }\end{array}$ & Ashe et al., 1976 \\
\hline $6-10$ & Cat $(\mathbf{P})$ & W. noise & 1 & $75 \mathrm{~dB}$ & $\begin{array}{l}\text { Forepaw } \\
\text { shock }\end{array}$ & 0.500 & $25-30 \mathrm{~V}$ & 1 & $\bar{x}=60$ & $\begin{array}{l}\text { Sensitiz. } \\
\text { W }\end{array}$ & Ashe et al., 1978a \\
\hline $2-10$ & Cat (P) & W. noise & 5 & $85 \mathrm{~dB}$ & $\begin{array}{l}\text { Forelimb } \\
\text { shock }\end{array}$ & 0.500 & $25 \mathrm{~V}$ & 5 & $\bar{x}=90$ & $\begin{array}{l}\text { Sensitiz. } \\
\text { W }\end{array}$ & Oleson et al., 1975 \\
\hline $2-5$ & Cat $(P)$ & Tone & $\begin{array}{l}0.100 \\
0.300\end{array}$ & $30-85 \mathrm{~dB}$ & $\begin{array}{l}\text { Forepaw } \\
\text { shock }\end{array}$ & 0.200 & $2-9 \mathrm{~mA}$ & $?$ & $\bar{x}=40$ & $\begin{array}{l}\text { Sensitiz. } \\
\text { W }\end{array}$ & Diamond, 1985 \\
\hline
\end{tabular}

Table A9

Respiration

\begin{tabular}{|c|c|c|c|c|c|c|c|c|c|c|c|}
\hline 1st CR & Subject & CS Type & $\begin{array}{c}\text { CS } \\
\text { Duration } \\
\text { (sec) }\end{array}$ & $\begin{array}{c}\text { CS } \\
\text { Intensity }\end{array}$ & US Type & $\begin{array}{l}\text { US } \\
\text { Duration } \\
\text { (sec) }\end{array}$ & $\begin{array}{l}\text { US } \\
\text { Intensity }\end{array}$ & $\underset{(s e c)}{|S|}$ & ITI (sec) & Control & Citation \\
\hline $2-5$ & Fish (P) & Light & 10 & $?$ & $\begin{array}{l}\text { Body } \\
\text { shock }\end{array}$ & 0.100 & $5 \mathrm{~mA}$ & 10 & $\bar{x}=90$ & None & Davis \& Holmes, 1971 \\
\hline $2-20$ & Pigeon (R) & Light & 6.5 & $?$ & Footshock & 0.500 & $?$ & 6 & $\bar{x}=444$ & None & $\begin{array}{l}\text { Durkovic \& Cohen, } \\
1969\end{array}$ \\
\hline $2-10$ & Rabbit (R) & Tone & 4 & $72 \mathrm{~dB}$ & Eyeshock & 1 & $20 \mathrm{~mA}$ & 4 & 120 & Sensitiz. & Yehle et al., 1967 \\
\hline $2-20$ & Pigeon (R) & Light & 6.5 & $?$ & Shock & 0.500 & $3-7 V$ & 6 & $\bar{x}=444$ & Sensitiz. & $\begin{array}{l}\text { Cohen \& Durkovic, } \\
1966\end{array}$ \\
\hline $11-20$ & Lizard (R) & $\begin{array}{l}\text { Light+ } \\
\text { tone }\end{array}$ & 11 & $?$ & Legshock & 1 & $0.1 \mathrm{~mA}$ & 10 & 105 & None & $\begin{array}{l}\text { Davidson \& Richardson, } \\
1970\end{array}$ \\
\hline $6-10$ & Fish (R) & Light & 5.5 & $395 \mathrm{Ix}$ & $\begin{array}{l}\text { Body } \\
\text { shock }\end{array}$ & 0.500 & $4.5 \mathrm{~V}$ & 5 & $\bar{x}=55$ & Random & Wolach et al., 1977 \\
\hline 5 & Fish (R) & Light & 4 & $0.03 \mathrm{ftc}$ & $\begin{array}{l}\text { Body } \\
\text { shock }\end{array}$ & 0.050 & $7 \mathrm{~mA}$ & 4 & $\bar{x}=240$ & $\begin{array}{l}\text { Sensitiz. } \\
\text { WI/ND }\end{array}$ & Woodard, 1971 \\
\hline 2 & Fish (R) & Light & 4 & $0.19 \mathrm{ftc}$ & $\begin{array}{l}\text { Body } \\
\text { shock }\end{array}$ & 0.050 & $7 \mathrm{~mA}$ & 4 & $\bar{x}=240$ & $\begin{array}{l}\text { Sensitiz. } \\
\text { WI/ND }\end{array}$ & Woodard, 1971 \\
\hline
\end{tabular}




\section{APPENDIX B \\ Experiments Used for Matching Rapidly Acquired ("Fast") and Slowly Acquired ("Slow") Conditioned Responses on US Intensity and Intertrial Interval}

\section{Matching on US Intensity}

Rapidly Acquired Conditioned Responses Blood Pressure

Rat: Hoffman \& Fitzgerald, 1978.

$$
\text { Conditioned Suppression }
$$

Rat: Annau \& Kamin, 1961; Burdick \& James, 1973; James, Shangi, Pangman, \& Mostoway, 1973; Kamin, 1961, 1963; Randich \& Maixner, 1981; Riess \& Farrar, 1973.

Galvanic Skin Response

Human: Morrow, Seiffert, \& Kramer, 1970; Schramm \& Kimmel, 1970; Silver \& Greco, 1975.

Rat: Holdstock \& Schwartzbaum, 1965.

\section{Heart Rate}

Lizard: Davidson \& Richardson, 1970.

Rabbit: Stava \& Hupka, 1976.

Rat: Holdstock \& Schwartzbaum, 1965.

$$
\text { Pupil }
$$

Cat: Oleson, Westenberg, \& Weinberger, 1972.

$$
\text { Respiration }
$$

Fish: Woodard, 1971.

Lizard: Davidson \& Richardson, 1970.

Slowly Acquired Conditioned Responses

$$
\text { Eyelid }
$$

Rabbit: Frey \& Butler, 1973; Frey \& Ross, 1968.

$$
\text { Flexion }
$$

Dog: Barnes, 1956 (leg).

Lizard: Davidson \& Richardson, 1970 (leg).

Rat: Chacto \& Lubow, 1967 (tail); Ginn, Valentine, \& Powell, 1983 (leg); Miller, Greco, \& Vigorito, 1981 (tail).

\section{Nictitating Membrane}

Rabbit: Gormezano \& Coleman, 1975; Graves \& Solomon, 1985; Kehoe \& Gormezano, 1974; Leonard, Fishbein, \& Monteau, 1972; Mis \& Moore, 1973; Mitchell, 1973; Plotkin \& Oakley, 1975; Snyder \& Papsdorf, 1968.

\section{Matching on Intertrial Interval}

Rapidly Acquired Conditioned Responses

$$
\text { Blood Pressure }
$$

Rabbit: Yehle, Dauth, \& Schneiderman, 1967.

$$
\text { Galvanic Skin Response }
$$

Cat: Van Twyver \& King, 1969.

Human: Champion, 1962; Kimmel, Kimmel, \& Silver, 1969; Prokasy \& Ebel, 1967; Schramm \& Kimmel, 1970.

\section{Heart Rate}

Rabbit: Yehle, Dauth, \& Schneiderman, 1967.

$$
\text { Pupil }
$$

Cat: Ashe, Cassaday, \& Weinberger, 1976; Diamond, 1985; Diamond \& Weinberger, 1984; Gerall \& Obrist, 1962; Oleson, Ashe, \& Weinberger, 1975; Oleson, Westenberg, \& Weinberger, 1972; Ryugo \& Weinberger, 1978; Weinberger, Hopkins, \& Diamond, 1984; Weinberger, Oleson, \& Haste, 1973.

\section{Respiration}

Fish: Davis \& Holmes, 1971.

Rabbit: Yehle, Dauth, \& Schneiderman, 1967.

Slowly Acquired Conditioned Responses

$$
\text { Eyelid }
$$

Rabbit: Frey \& Butler, 1973, 1977; Frey \& Ross, 1968; Gutmann, Brozek, \& Bures, 1972.

\section{Nictitating Membrane}

Rabbit: Berger \& Thompson, 1978; Grevert \& Moore, 1970; Kehoe \& Gormezano, 1974; Leonard, Fishbein, \& Monteau, 1972; Leonard \& Theios, 1967; Mitchell, 1973.

(Manuscript received January 27, 1992; revision accepted for publication April 7, 1992.) 